Helgoländer wiss. Meeresunters. 23, 38-79 (1972)

\title{
Structure and function of the locomotory system of Polyorchis montereyensis (Cnidaria, Hydrozoa)
}

\author{
W. B. Gladfelter \\ Bodega Marine Laboratory, University of California; \\ Bodega Bay, California, USA
}

\begin{abstract}
KURZFASSUNG: Struktur und Funktion des lokomotorischen Systems von Polyorchis montereyensis (Cnidaria, Hydrozoa). Mit Hilfe histologischer und kinematographischer Methoden wurden Bau und Funktion des lokomotorischen Systems der Anthomeduse Polyorchis montereyensis SkOgsBerc analysiert. Die Schwimmbewegungen resultieren aus der antagonistischen Wirkung der Muskulatur der Subumbrella und der elastischen Mesogloea. Struktur, Anordnung, Verteilung und Verankerung der Muskelzellen werden beschrieben. Die Körperschicht der Mesogloea besteht aus 5 Komponenten mit Skelettfunktion: der Matrix der Schirmmesogloea, einem System von Muskelfasern, der Stützlamelle, acht adradialen Verbindungssträngen von stark deformierbarer, fibrillenloser Mesogloea und der Mesogloea des Velums. Die Fribrillen und Verbindungsstränge der Mesogloea bewirken, daß die Schirmglocke während der Kontraktion deformiert werden kann. Die Funktion des Velums sowie die kontinuierlichen Veränderungen der Glocke in bezug auf Form und Lage während des Schwimmvorgangs, insbesondere die Geschwindigkeit der Kontraktion, des Wasserausstoßes und der Fortbewegung bei Individuen verschiedener Größe, wurden eingehend untersucht. Kleinere Medusen schwimmen relativ schneller als größere, was hauptsächlich auf stärkere Kontraktionen des Velums zurückzuführen ist.
\end{abstract}

\section{INTRODUCTION}

It has long been recognized that medusae propel themselves by rhythmic sequences of contractions and expansions of the body whereby ... "the walls of the bell are drawn together; the capacity of the bell being thus diminished, water is ejected from the open mouth backwards and the consequent reaction propels the animals forwards" (Romanes 1885). The functional morphology of the system that effects this locomotion has not been analyzed for any medusa. In fact, the concept of the medusa as a functioning musculoskeletal system has been discussed only briefly by G. CHApMaN (1958) in a general sense, G. Chapman (1959) in Pelagia noctiluca, Gutmann $(1965,1966 \mathrm{a}, \mathrm{b})$ in Rbizostoma octopus, and D. M. Chapman (1968) in Obelia.

Other workers have described some components of the swimming system in varying degrees of detail, but in no instance has the structure or function of the propulsive mechanism as a whole been described; in fact the very existence of certain conspicuous morphological features remains absent from the literature. It was therefore the aim of the present study to describe the actual components of the locomotory 
system in the hydrozoan medusa Polyorchis montereyensis Skogsberg and to analyze the means by which these components act to deform the bell and effect locomotion. In addition, a number of the parameters of swimming have been measured, calculated and correlated to yield a quantitative description of this activity. In a second paper, representatives of nearly all the cnidarian orders in which the medusa is conspicuous in the life cycle are examined in less detail to determine how their locomotory mechanims differ both structurally and functionally from that of Polyorchis montereyensis.

$P$. montereyensis is the most conspicuous medusa found in harbors along the coast of central California, yet most of its natural history remains a mystery. Stages in the life cycle between the advanced planula and young medusa several millimeters high are unknown (SKogsberg 1948, NAGAo 1963). Growth rates, longevity and duration of pelagic life are likewise unknown. Scattered individuals have been found in every month of the year except February, but the several species are most common from April to October (GladfeLter, unpublished). Specimens were almost always found in water above sand or mud bottoms: Monterey Harbor, San Francisco Bay, Bodega Bay, and Bull Harbor, British Columbia. When present in large numbers, as at Bull Harbor in September, 1970, individuals were evenly distributed in the water column. Animals in nature alternate periods of swimming activity with periods of quiescence, when they drift with their tentacles extended, forming a "food web". In the laboratory $P$. montereyensis spends much of its time resting upright on the sand bottom, and it is suspected that this occurs in nature as well.

\section{MATERIALS AND METHODS}

Individuals of Polyorchis montereyensis were collected from the floating docks in the Municipal Marina at Monterey, California by dipping them out of the water in a small enamelled pan. This method of collection minimizes damage to the delicate epithelia. Animals were maintained in glass aquaria supplied with cool, running seawater at the Hopkins Marine Station. Essentially three categories of analysis were employed in the present investigation: (1) those for determining the structure of the locomotory system, (2) those dealing with deformation and operation of the bell during swimming, and (3) those used to analyze and quantify the actual swimming of P. montereyensis.

Anatomical investigations were carried out by two methods. Sections about $1 \mathrm{~mm}$ thick of fresh and recently formalin-fixed medusae were cut by hand with an unused razor blade. Such sections were then placed on a chambered microscope slide immediately, or after staining in slightly acidified $1 \%$ aqueous Fast Green FCF, and then examined by dissecting, compound or phase contrast microscope. In addition to these studies, whole medusae, $20 \mathrm{~mm}$ or less in bell height were relaxed in isotonic $(7.3 \mathrm{~g} / \mathrm{l})$ $\mathrm{MgCl}_{2}$ then fixed in ice-cold Bouin's fluid. They were subsequently embedded in paraffin by standard histological technique and sections 4-10 $\mu \mathrm{m}$ were cut, and stained by Masson's Trichrome (GAligher \& Kozloff 1964).

The mechanism of bell deformation was analyzed by comparing sets of photographs of individual medusae taken in relaxed and contracted conditions. A single 
lens reflex camera and electronic flash were used to take the photos. Animals photographed in lateral view were placed in chambers whose depth from front to back was only slightly greater than the diameter of the medusa. Animals photographed along the oral-aboral axis (to be referred to as axial or polar views) were placed in a square glass container and confined in one of several small chambers consisting of a series of 8 thin glass rods inserted vertically into a piece of black plexiglass; the water was maintained just slightly deeper than the height of the medusa. In both instances the apparatus was designed to restrict displacement of a "swimming" medusa without hampering the normal nature of the swimming contraction. A number of pairs of photos thus obtained were measured and the results interpreted. In some instances fine glass needles were inserted in horizontal or vertical rows in the bell in order to determine the amount of local deformation, and the animals photographed as before.

Quantitative data on the swimming of $P$. montereyensis were obtained by macrocinematography. An animal to be photographed was placed in one of several narrow chambers immersed against the front plate of a large aquarium. The size of the chamber used depended on the size of the medusa: chamber depth from front to back was generally about twice the diameter of the medusa and chamber height was five to eight times the height of the bell. The movement of the animal was thus confined to an area essentially in a plane parallel to the plane of the film in the camera. The plexiglass back of the chamber was painted black, with a one or two $\mathrm{cm}$ grid etched on it. The bottom and sides of the chamber were of plastic screen to allow free passage of water through the chamber. One, two or three 250 watt photofloods were aimed into the chamber from the side or from above, positioned so as to avoid reflection from the glass front of the chamber. Cold water continually circulated through the tank, and a thermometer was kept at hand to insure that the water temperature never rose above $17^{\circ} \mathrm{C}$ in the chamber. A Bolex $16 \mathrm{~mm}$ reflex cine camera with a $75 \mathrm{~mm}$ lens was mounted on a large tripod in front of the chamber. Appropriate extension tubes were inserted between the lens and camera to obtain the desired magnification. Use of a telephoto lens permitted a more convenient working distance for close-ups, and reduced the effective angle through which a medusa would swim during a particular sequence, thus maintaining the essentially parallel relationship between the plane of locomotion and the film. Negative Plus-X film (Eastman Kodak) was used, to produce a fine grained image with the subject appearing darker than the background for ease of tracing. By means of a Film Analyst (Lafayette Instrument Co.) the shape of a swimming animal could be traced from successive frames at great magnification, and the position of the animal in relation to the fixed grid on the back of the chamber could be recorded. Once the outline of the medusa in a given frame had been traced, it was subdivided into a number of equally spaced segments by horizontal lines (Fig. 19). These were measured, the scale provided by the grid. The circumference and volume of the bell or subumbrellar cavity could be calculated by thus dividing the bell tracing into a number of discshaped increments. The change in position of the medusa during successive intervals could be measured from the grid and velocity calculations were made therefrom. 


\section{RESULTS}

\section{Anatomy of the locomotory system}

The bell of Polyorchis montereyensis is usually taller than wide (Fig. 1). According to SKogsBerg (1948) the average height to width ratio is $1.2 /$. The lateral wall of the bell is broadly convex, being widest about midbell or slightly below, and narrowing a small amount toward the margin. The bell is thickest at the apex, or aboral pole,

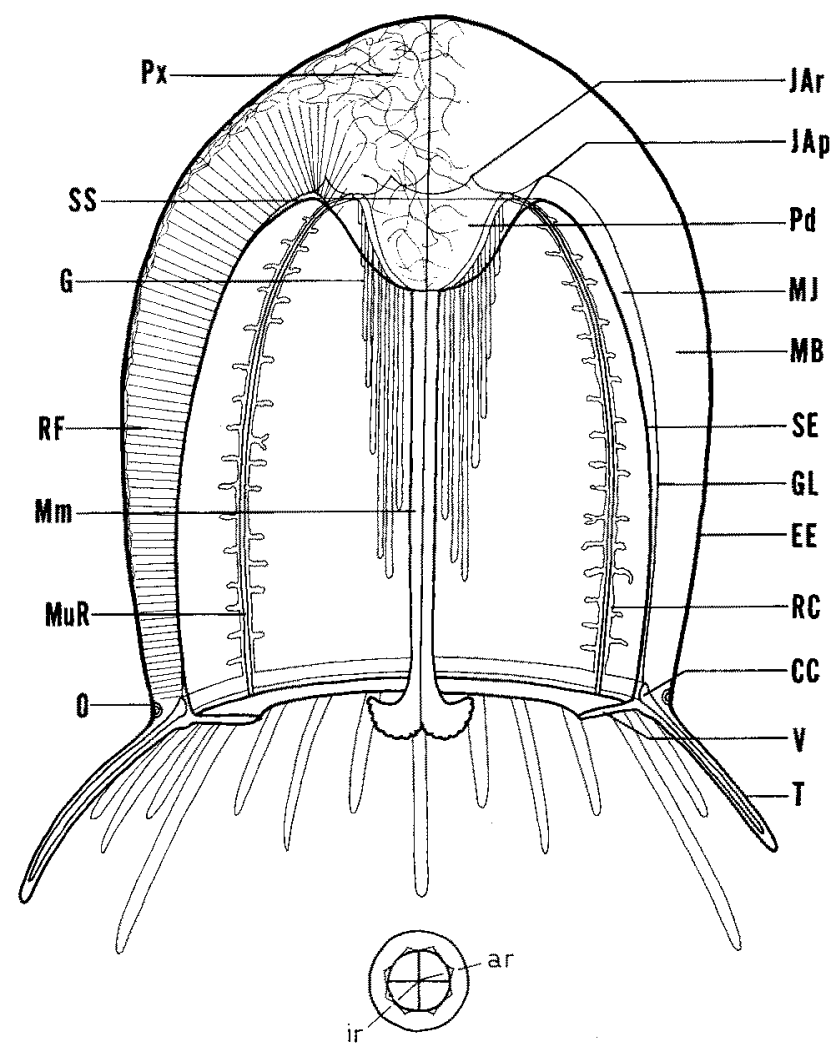

Fig. 1: Longitudinal section through the bell of Polyorchis montereyensis; interradial (ir) section (left) and adradial (ar) section (right). $A r$ adradius; $C C$ ring canal; $E E$ exumbrella; $G$ gonad; $G L$ gastrodermal lamella; Ir interradius; $J A p$ apical joint; $J A r$ adradial joint; $M B$ bell mesoglea; $M J$ joint mesoglea; $M m$ manubrium; $M u R$ radial muscle; $P d$ peduncle; $P x$ mesogleal fiber plexus; $R C$ radial canal; $R F$ radial mesogleal fiber; $S E$ subumbrella; $S S$ subumbrellar summit; $T$ tentacle; $V$ velum; $O$ ocellus

where a moderate peduncle projects into the subumbrellar cavity. The circular trough surrounding the base of the peduncle at the top of the subumbrellar cavity is the subumbrellar summit. The bell wall gradually decreases in thickness toward the margin, where it is about half as thick as at the subumbrellar summit. The midbell thickness is 
generally from $11-17 \%$ of the bell diameter at the same level. The average ratio of the height of the subumbrellar cavity to its width is $1.2 / 1$. Usually the subumbrellar cavity is widest at about the midbell region, but occasionally the widest part is closer

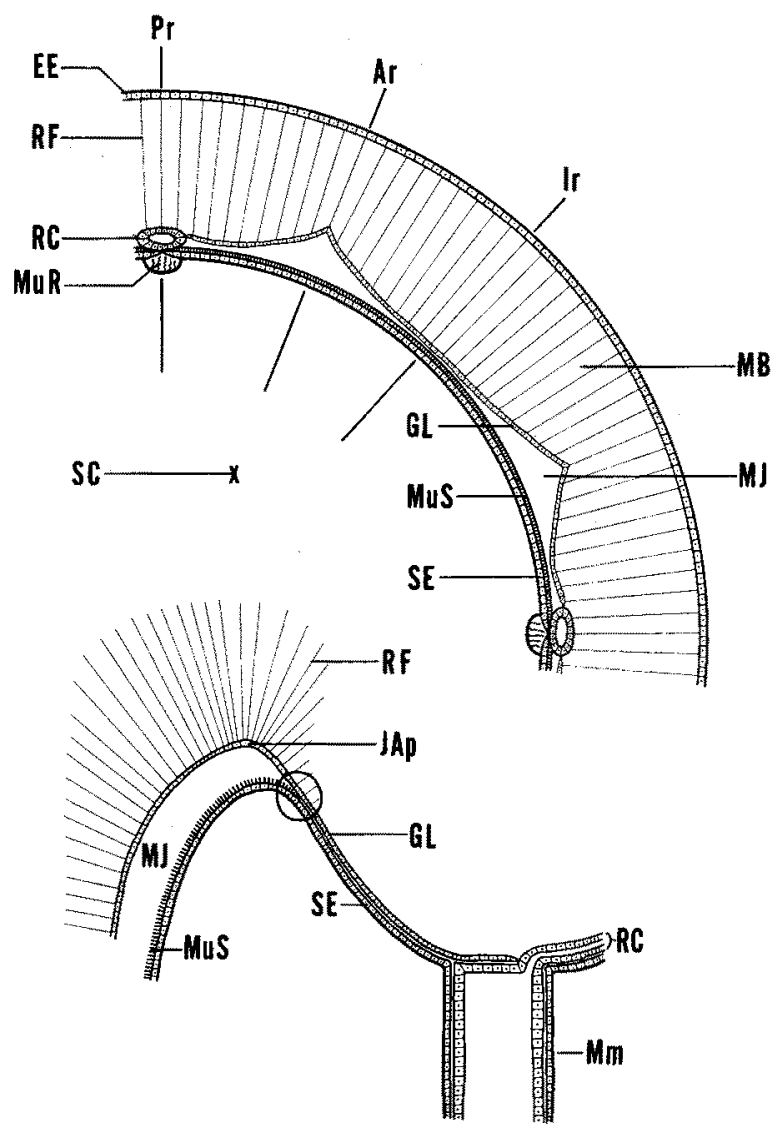

Fig. 2 (above): Diagrammatic horizontal section through one quadrant of Polyorchis montereyensis at midbell. Ar adradius; $E E$ exumbrellar epidermis; $G L$ gastrodermal lamella; $I r$ interradius; $J A p$ apical joint; $M B$ bell mesoglea; $M J$ joint mesoglea; $M m$ manubrium; $M u R$ radial muscle; $M u S$ swimming muscle; $P r$ perradius; $R C$ radial canal; $R F$ radial mesogleal fiber; $S C$ subumbrellar cavity; $S E$ subumbrellar epidermis

Fig. 3 (below): Vertical section through the region of the subumbrellar summit and peduncle in Polyorchis montereyensis; adradial section (left) and perradial section (right). Notice especially the encircled region where the termination of the swimming muscle coincides with the termination of the radial mesogleal fibers and the anchorage of the gastrodermal lamella to the subumbrellar epidermis

to, or even at, the margin. In any case it is approximately cylindrical. In cross section (Fig. 2) both exumbrellar and subumbrellar outlines are essentially circular, with a slight octagonality sometimes in evidence in the former. Further details of the bell proportions can be found in SKOGSBERG (1948). 


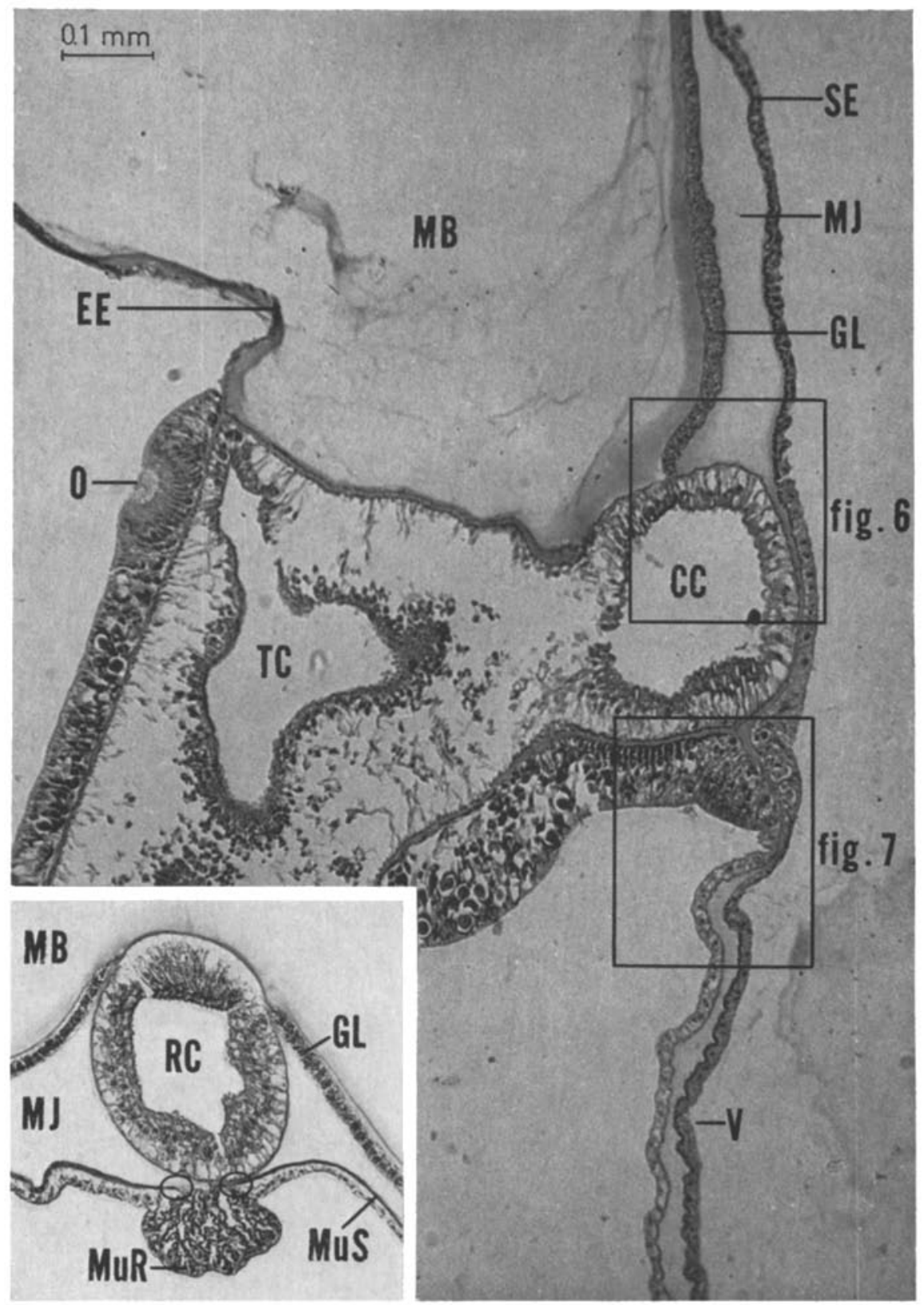

Fig. 5

Fig. 4

Fig. 4: Longitudinal section through the bell margin of Polyorcbis montereyensis (Bouin's; $6 \mu \mathrm{m}$ paraffin section; Masson's Trichrome Stain). CC ring canal; $E E$ exumbrellar epidermis; $G L$ gastrodermal lamella; $M B$ bell mesoglea; $M J$ joint mesoglea; $O$ ocellus; $S E$ subumbrellar epidermis; TC tentacle canal; $V$ velum; $M u R$ radial muscle band; $M u S$ swimming muscle; $R C$ radial canal

Fig. 5: Cross section through a radial canal of Polyorchis montereyensis at about midbell (Bouin's; $6 \mu \mathrm{m}$ paraffin section; Massons's Trichrome Stain). The termination of the swimming muscle beneath the radial muscle band is shown in the two circled areas 
The manubrium is borne on the peduncle and extends to about the bell margin. Its gastrodermis continues up the peduncle as four radial canals which then turn and course downward to join the ring canal at the bell margin (Figs. 1, 3). The radial canals have short, blind lateral branches. Extensions of the gastrodermal canal system proceed into the numerous marginal tentacles, each of which bears an ocellus on the outer side of its base (LITTLE 1914, EAKIN \& Westrall 1962). Canals also extend into the gonads, which depend from beneath the radial canals on the peduncle (Fig. 1). The radial canals establish the principal radial axes, or perradii, of the bell, dividing it into four equal quadrants (Fig. 2). The four interradii lie midway between the perradii; between the interradii and the perradii are the adradii.

Lying between adjacent radial canals in the mesoglea of the bell is the gastrodermal lamella, a sheet of cuboidal cells one cell thick which extends from the base of the manubrium to the ring canal (Figs. 2,3,4,6). This enigmatic layer is not in cellular continuity with radial and ring canals but is anchored to them via the basement membrane (Fig. 5). The layer is electrophysiologically active and important in conducting the crumpling response (MACKIE \& PASSANO 1968). Along the interradii the gastrodermal lamella is anchored to the subumbrellar epidermis by a thin layer of connective tissue, the supporting lamella or basement membrane. Between the per- and interradii the gastrodermal lamella is scalloped into eight longitudinal adradial ridges, seen best in cross section (Figs. 2, 12). Because of their function these ridges will be referred to as longitudinal or adradial "joints", a term applied to analogous structures in the scyphomedusan Cotylorbiza by BAuen (1927). They extend from above the subumbrellar summit nearly to the margin of the bell. In the relaxed bell they are most pronounced, in terms of acuteness and height above the subumbrellar surface, near the subumbrellar summit; they become progressively less pronounced toward the margin (Fig. 14). Interradial anchorage between the gastrodermal lamella and the subumbrellar epidermis becomes increasingly broad toward the margin, as the joints become less pronounced. Toward the subumbrellar summit the zone of interradial anchorage of the subumbrellar epitheliomuscular sheet narrows and just below the level of the subumbrellar summit the gastrodermal lamella completely loses interradial contact with the subumbrellar epidermis and diverges from the latter to form a ridge at its highest level before descending onto the peduncle (Figs. 1, 3). This ridge, the circular apical joint, is roughly octagonal, forming apices in the adradii where it joins the longitudinal joints. After descending onto the peduncle the gastrodermal lamella again comes into contact with the basement membrane of the epidermis.

The great bulk of the bell consists of transparent, noncellular mesoglea. This is completely segregated into outer and inner layers which are separated by the intervening gastrodermal lamella (Figs. 2, 12). The outer and much thicker layer of mesoglea, lying between the exumbrellar epidermis and the gastrodermal lamella is the bell mesoglea. It has the consistency of a firm gel. In a cross section of the midbell region, the bell mesoglea of the perradial sectors is $20-25 \%$ thicker than that of the interradial sectors (Figs. 12,13). Usually the interradial sectors ar wider than the perradial sectors. Above the midbell level the bell mesoglea becomes gradually thicker; toward the margin it becomes thinner.

The bell mesoglea is traversed by numerous radially arranged highly refractile 
fibers (Chapman 1953a, 1959, Boullon \& Vandermeerssche 1957, Mackie \& Mackie 1967). Because of their high refringence these fibers are readily observed under the dissecting microscope. The fibers are perpendicular to the exumbrellar surface and uniformly distributed around its perimeter. On the subumbrellar side they impinge on

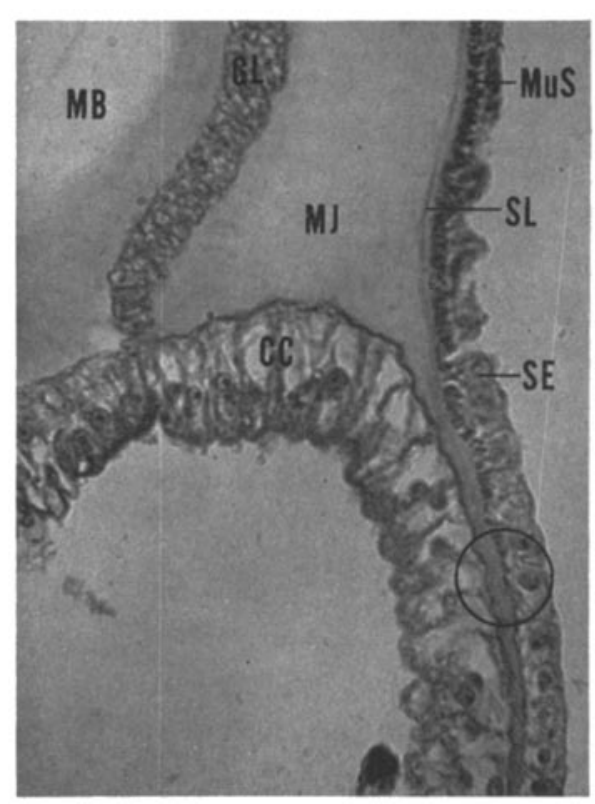

Fig. 6

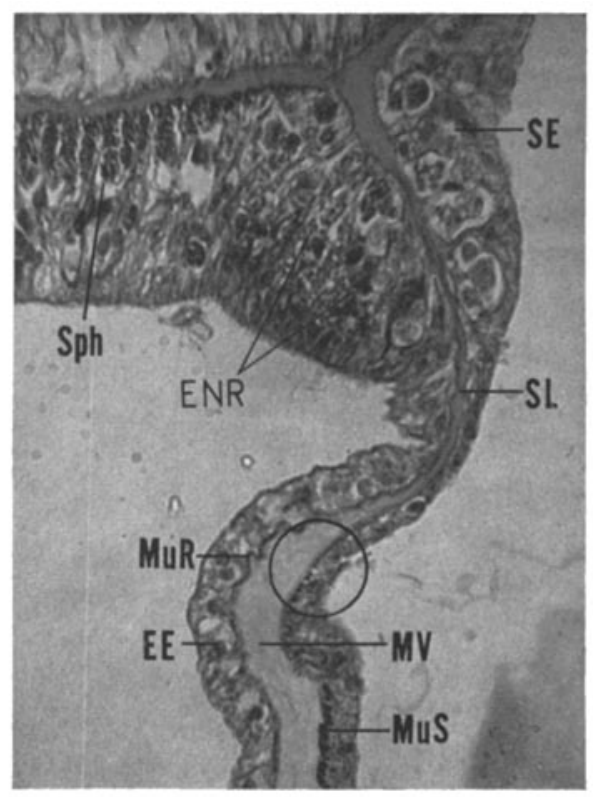

Fig. 7

Fig. 6: Region of termination of subumbrellar swimming muscle of Polyorchis montereyensis (circled); enlargement of portion of Figure 4. CC ring canal; $M B$ bell mesoglea; $M J$ joint mesoglea; $M u S$ swimming muscle; $S E$ subumbrellar epidermis; $S L$ supporting lamella (basement membrane); $E E$ exumbrellar epidermis (of velum); $M V$ velar mesoglea; $M u R$ radial muscle of velum; $S p h$ sphincter; $E N R$ exumbrellar nerve ring

Fig. 7: Base of velum of Polyorchis montereyensis (beginning of velar swimming muscle is circled); enlargement of portion of Figure 4. Notice thin region of dense connective tissue at the base of the velum

the gastrodermal lamella, and are perpendicular to the latter except near the vertices of the longitudinal and circular apical joints, where the fibers converge at acute angles (Fig. 9a), and also at the radial canals, where there is a slight convergence. Aboral and medial to the circular apical joint at the base of the peduncle, fiber development rapidly diminishes, and fibers disappear below the junction of the gastrodermal lamella and the epidermis on the peduncle (Fig. 3). Thus the apical mesogleal mass is virtually devoid of these straight fibers. There is, however, a loose plexus of fibers in this area (Fig. 1), which continues along the exumbrellar side of the bell wall as a thin layer parallel to and underlying the epidermis (Figs. 1, 8); this gradually disappears toward the margin. The bell mesoglea in the region of the plexus is softer than that in areas where the fibers are straight, and undergoes greater shrinkage on fixation, as seen in 


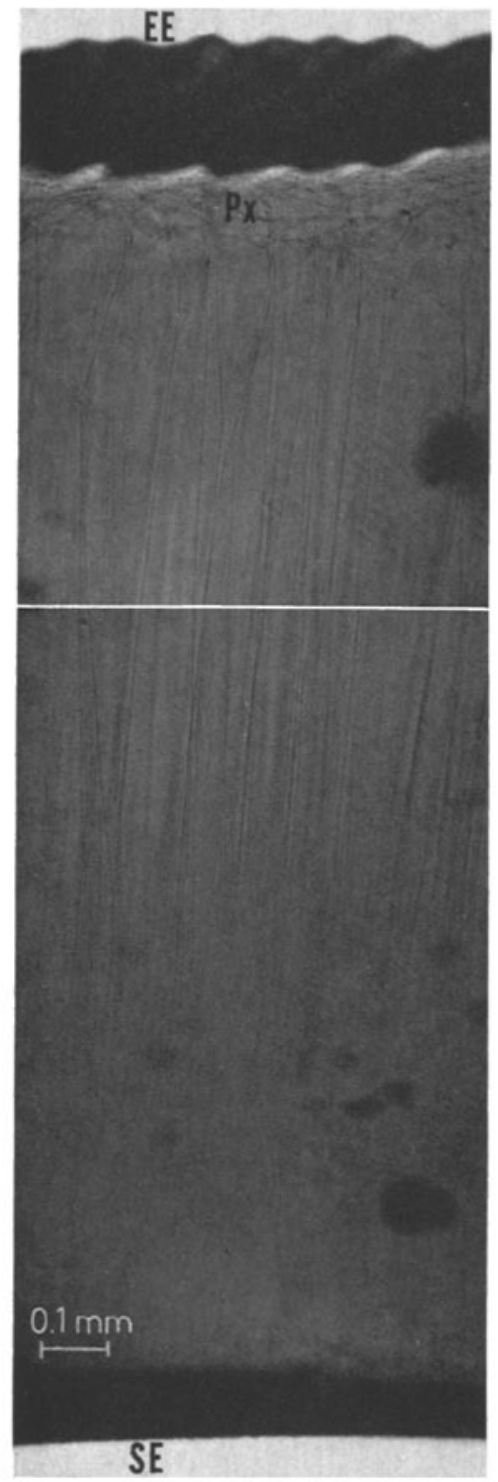

Fig. 8
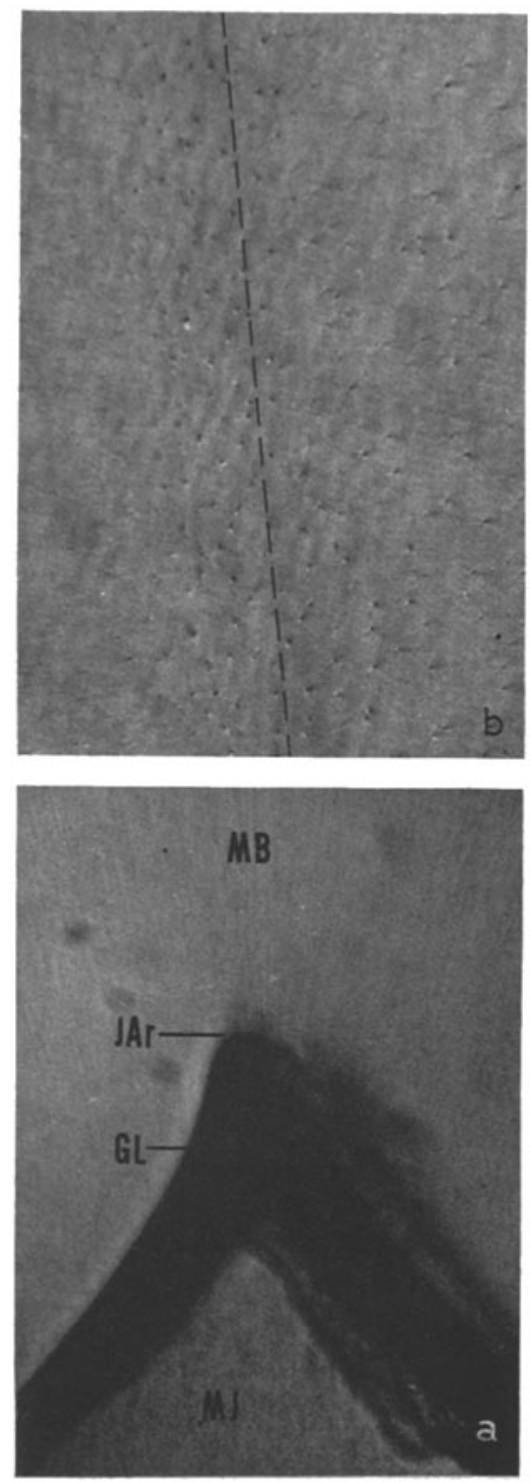

Fig. 9

Fig. 8: Morphology of the radial mesogleal fibers of the midbell region of Polyorchis montereyensis (hand-cut section of $\mathrm{HCHO}$ fixed material stained with dilute aqueous Fast Green). $E E$ exumbrellar epidermis; $P x$ exumbrellar fiber plexus; $S E$ subumbrellar epidermis

Fig. 9: Concentration of mesogleal fibers along the apex of an adradial joint of Polyorchis montereyensis (hand-cut sections of $\mathrm{HCHO}$ fixed material stained in dilute aqueous Fast Green). (a) View of cross section of the joint. (b) View of the joint from the exumbrellar surface, focused near apex of joint. $J A r$ apex of the adradial joint; $G L$ gastrodermal lamella; $M B$ bell mesoglea; $M J$ joint mesoglea 
Table 1

Densities of mesogleal fibers at successive levels of the bell in Polyorchis montereyensis. The data in this table were obtained by cutting meridional strips of the bell from margin to subumbrellar summit. Each of these was then placed on a microscope slide on which a chamber had been built, and covered with a cover slip. At each of the indicated levels (") the mesoglea was focused on at the level at which the fibers were unbranched, and then photographed at $100 \times$. An area $0.5 \times 0.5 \mathrm{~mm}$ was marked off on the photograph and the number of fibers counted and multiplied by 4 to give \# of fibers $/ \mathrm{mm}^{2}$

\begin{tabular}{|c|c|c|c|c|c|}
\hline Individual & $\begin{array}{c}\text { Bell } \\
\text { height } \\
(\mathrm{mm})\end{array}$ & Level* & interradial & $\begin{array}{c}=\text { of fibers } / \mathrm{mm}^{2} \\
\text { adradial }\end{array}$ & perradial \\
\hline \multirow[t]{4}{*}{1} & 7 & 0.2 & 1230 & 1060 & 1100 \\
\hline & & 0.4 & 1140 & 1240 & 760 \\
\hline & & 0.6 & 770 & 1360 & 530 \\
\hline & & 0.8 & 330 & 980 & 280 \\
\hline \multirow[t]{4}{*}{2} & 8 & 0.2 & 1290 & - & - \\
\hline & & 0.4 & 1180 & 1670 & - \\
\hline & & 0.6 & 780 & - & - \\
\hline & & 0.8 & 430 & - & - \\
\hline \multirow[t]{4}{*}{3} & 15 & 0.2 & 390 & - & - \\
\hline & & 0.4 & 350 & 660 & - \\
\hline & & 0.6 & 260 & 300 & 150 \\
\hline & & 0.8 & 210 & - & - \\
\hline \multirow[t]{4}{*}{4} & 18 & 0.2 & 360 & 520 & 140 \\
\hline & & 0.4 & 250 & 490 & 150 \\
\hline & & 0.6 & 110 & 170 & 90 \\
\hline & & 0.8 & 90 & 80 & 60 \\
\hline \multirow[t]{4}{*}{5} & 28 & 0.2 & 160 & - & - \\
\hline & & 0.4 & 100 & - & - \\
\hline & & 0.6 & 60 & - & - \\
\hline & & 0.8 & 40 & - & - \\
\hline
\end{tabular}

Figure 8 , where it has been thrown into a series of wrinkles as a result of fixation. The number of perpendicular fibers per unit area is greatest near the bell margin and decreases gradually toward the apex (Table 1). Fiber density is also greater interradially than perradially at any given level of the bell.

The straight fibers branch repeatedly toward the subumbrella into a narrow cone of finer and finer fibers which become difficult to resolve with the light microscope (Fig. 8). Toward the exumbrella there is much less branching, and the branches are continuous with the fibers of the aforementioned loose plexus. In a stained preparation each fiber measures about $1.5 \mu \mathrm{m}$ in diameter midway along its length.

Paraffin sections stained with Masson's Trichrome reveal a deeply green-staining layer beneath ex- and subumbrellar epidermis, and between the gastrodermal lamella and the bell mesoglea, indicating a relatively high concentration of mesoglea here. This is the supporting lamella ("Stützlamelle") of Hertwig \& HERTwig (1880). It is a basement membrane supporting all the cellular layers of the medusa. The confluence of the mesogleal fibers with the basement membrane of the gastrodermal lamella provides a secure anchorage between the bell mesoglea and the lamella. 
Isolated between the gastrodermal lamella and the basement membrane of the subumbrellar epidermis lies the inner region of mesoglea, hereafter called the joint mesoglea (Figs. 2, 9a, 12). It is physically quite different from the bell mesoglea, and contains no fibers of any kind, visible by light microscopy, in fresh, formalin fixed, or paraffin sectioned material (Fig. 9a); the existence of this inner mesoglea has previously been noted only by L. Agassiz (1862) in several anthomedusae, and D. M. Chapman et al. (1962) have shown it clearly in an electron micrograph. In the lateral bell wall this joint mesoglea occupies the more or less triangular adradial regions and is absent at the per- and interradii. Near the summit of the subumbrella where the gastrodermal lamella separates from the underlying epidermal sheet in the interradii, the joint mesoglea is continuous in each quadrant (Fig. 14a). The joint mesoglea appears at first to be almost fluid in nature (Agassiz 1862, refers to this region as a "sinus"); this is not the case. Injection of methylene blue into the joint mesoglea at various positions reveals that it is a very deformable gel, but not fluid. After repeated contractions the dye retains its original position and configuration, indicating no bulk displacement as would be the case if it were fluid. Furthermore the very soft joint mesoglea can be dissected out and its gelatinous nature demonstrated.

The musculature of Polyorchis montereyensis consists of the following components: the subumbrellar layer of swimming muscle; four bands of longitudinal smooth muscle lying on the subumbrellar side of the radial canals and extending from the base of the manubrium to the bell margin (Figs. 1, 5); the velar musculature (Figs. 7, 16b); a sphincter of circular smooth muscle lying below the ring canal (Figs. 4, 7); and the muscles of the tentacles and manubrium. Of these, only the subumbrellar layer and the velar muscles play important roles in swimming.

The swimming muscle is an integral part of the subumbrellar epidermis. It consists of four sheets, each one continuous between two adjacent radial canals (Fig. 2). Each sheet extends longitudinally from the base of the peduncle, just at the line where the descending gastrodermal lamella meets the epidermis of the peduncle (Fig. 3), to the level of the middle of the ring canal (Figs. 4,6). The contractile elements are bandlike striated muscle fibers which are extensions of the subumbrellar epidermal cells (Fig. 10), and are oriented circularly around the subumbrella. The individual muscle processes are up to $90 \mu \mathrm{m}$ long, and are in staggered position in the sheet (Fig. 10a). One muscle band may underlie as many as six cells; since twelve to fifteen bands underlie any one cell, it is likely that each epitheliomuscular cell of this type bears two or three striated muscle bands. The actual morphology of this epitheliomuscular cell is probably very similar to that figured by FRASER (1962), for the limnomedusan Gonionemus. The muscle fibers as seen with trichrome staining of paraffin sections are securely embedded in the supporting lamella (Fig. 10c). Because of its birefringence the extent of the striated muscle sheet can be seen even in whole, unstained animals with proper lighting. The circular muscle sheet terminates beneath each radial canal; its terminus is somewhat overlapped by the radial smooth muscle band (Fig. 5).

The velum is located just inside the bell margin and projects in the same plane as the opening of the bell (Fig. 1). In P. montereyensis it is relatively well developed, its width being about $30 \%$ of the radius of the bell aperture. The epithelial cells of its upper surface, facing the subumbrellar cavity, bear circularly oriented striated muscle 

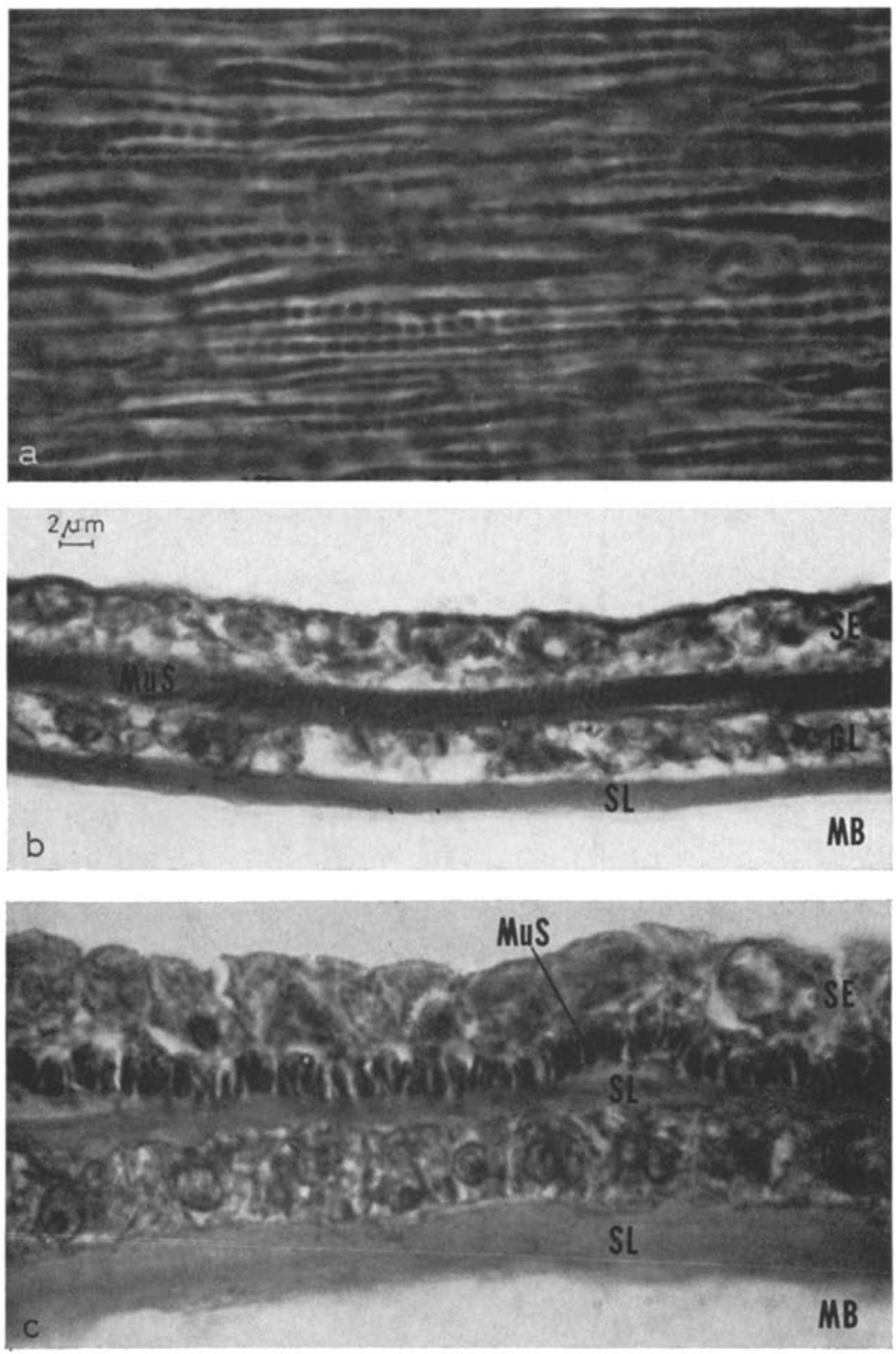

Fig. 10: Histology of the swimming muscle of Polyorchis montereyensis (Bouin's; $6 \mu \mathrm{m}$ paraffin section; Masson's Trichrome Stain). (a) Arrangement of striated muscle processes to form a sheet, as seen from the subumbrellar surface. (b) Horizontal section through the bell wall, showing the striated muscle processes in lateral view. (c) Vertical section through the bell, showing the muscle processes in cross section. $G L$ gastrodermal lamella; $M B$ bell mesoglea; $M u S$ circular swimming muscle; $S E$ subumbrellar epidermis; $S L$ supporting lamella (basement membrane) 
bands forming a continuous sheet identical to that of the subumbrellar wall (Fig. 7). However, the two sheets are separated by a distinct gap in which the subumbrellar nerve ring is located (Figs. 4, 6, 7); the subumbrellar sheet terminates at the middle of the ring canal and the velar layer begins at the base of the velum. Epithelial cells of the exumbrellar (lower) side of the velum bear radially oriented smooth muscle processes, which are arranged to form a continuous sheet. The radial fibers are not bandlike but rather cordlike, and smaller in cross-sectional area than the circular muscle processes. Between the two epithelia is a thin but quite firm mesoglea, to which the subumbrellar and exumbrellar muscle processes are anchored (Fig. 7). This mesogleal layer has a series of low circular ridges on the subumbrellar side and a series of low radial ridges on the exumbrellar side (Figs. 15, 16b). At the base of the velum where it attaches to the bell, the velar mesoglea is very thin, but stains densely (Fig. 7), indicating a concentration of mesoglea at this point.

\section{Functional analysis of bell deformation during swimming}

The swimming cycle of Polyorchis montereyensis consists of two distinct phases: the contraction and the recovery. The subumbrellar sheet of swimming muscle is the active agent during contraction, as it reduces the diameter of the bell. Four types of gross deformation of the bell occur when the subumbrellar swimming muscle contracts: the wall straightens and appears to elongate; the bell decreases in diameter and the wall becomes thicker; the bell bends octamerously or tetramerously around the adradial joints; and the bell flexes inward at the apical joint. At the same time, contraction of the velar circular muscle brings about a reduction in diameter and an increase in width of the velum. During contraction the mesoglea is the passive component, increasingly greater forces being generated within it until contraction is maximal. At this point potential energy built up in the mesoglea is released and overcomes the contracting force of the swimming muscle to bring about the recovery stage of the cycle, during which the bell and velum regain their original shape. An understanding of swimming must first rest on a clear understanding of the mechanism of contraction and expansion of the bell and velum. A functional analysis of the components follows.

The sheet of circularly oriented swimming muscle as seen in cross section, is divided into quadrants, which terminate on the subumbrellar side of the radial canals; here each quadrant of the sheet is firmly anchored between the radial canal and the radial muscle band (Figs. 3,5). The basement membrane of the epitheliomuscular sheet is anchored to the bell mesoglea also along the interradius via the gastrodermal lamella; if the muscle sheet is carefully peeled in the circular direction, it breaks in a jagged line just at the interradius. In a polar view of the swimming animal, the epitheliomuscular sheet is seen to remain anchored to the bell mesoglea at the interradii during contraction (Fig. 12b). Light microscopic examination of histological preparations and hand cut sections of formalin fixed medusae verify this anchorage. Near the summit of: the subumbrellar, however, where the gastrodermal lamella is no longer in contact with the basement membrane of the epithelial muscle (Figs. 1, 14), there is no interradial anchorage of the muscle to the bell mesoglea. Thus the swimming muscle is 

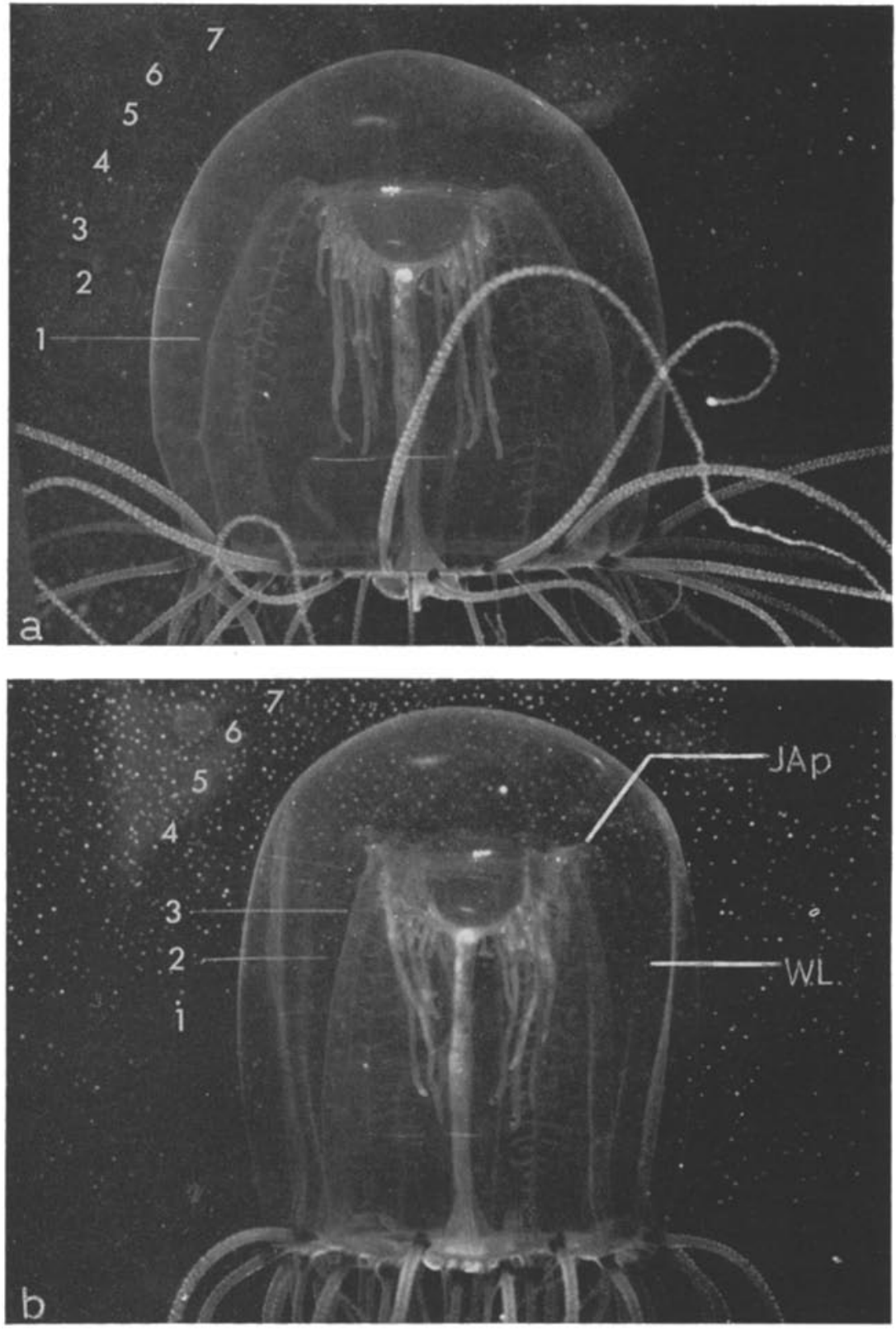

Fig. 11: Lateral view of the bell of Polyorcbis montereyensis in relaxed (a) and contracted (b) conditions. Fine glass needles inserted meridionally are numbered 1 through 7 and are referred to in the text. Particular points to be noticed are: (1) The action of the apical joint (JAp); (2) the development of fine longitudinal wrinkles in the exumbrella (WL); (3) the straightening and apparent lengthening of the lateral bell wall. JAp apical joint; $W L$ fine longitudinal wrinkles 
securely anchored to the bell mesoglea along the per-and interradii, except near the subumbrellar summit where interradial anchorage is lost.

Photographs of $P$. montereyensis in relaxed and contracted conditions were taken in lateral view at equal distance. Measurements of a number of these photographs reveal that though the bell as a whole elongates during contraction, this is due solely to straightening of the curvature of the lateral bell wall, i.e., there is no longitudinal flow of mesoglea or displacement of fluid within it (Fig. 11). This is an important point since it is the basis of the cross-sectional analysis to be discussed subsequently. The subumbrellar epitheliomuscular sheet is the same length from margin to summit in either the relaxed or contracted condition. Fine glass needles were inserted into the mesoglea in a longitudinal row (Fig. 11) in order to determine the amount and location of any change in the exumbrellar surface in lateral view during contraction. The exumbrella below the level of the subumbrellar summit actually shortens by about $5 \%$, due to compression as the bell wall straightens. This is enough to cause formation of a few small transverse wrinkles in the exumbrellar epithelium (Fig. 12b).

Photographs were taken of relaxed and contracted animals from above the aboral pole so that the middle latitude of the bell was in focus. During contraction the internal and external diameters of the bell decrease. In 39 cases examined using 13 different medusae, the average circumference of the subumbrella decreased by $37 \%$ during contraction. This will be discussed more fully later. As a result of the decrease in circumference of the exumbrella, fine longitudinal wrinkles develop (Figs. 11b, 12b). As the bell decreases in diameter, it thickens. Thickening, however, is not uniform along all radii. In polar view the exumbrella becomes octamerously or tetramerously scalloped (Fig. 12b), bulging outward at the adradii and bending inward per- and interradially (more so in the latter). The bell is always slightly thicker at the perradii than at the interradii both before and during contraction; sometimes there are even small secondary bulges perradially (Fig. 12b) in the contracted condition. In Figure 13 the actual deformation undergone by the bell during contraction is diagrammed, traced from photographic enlargements. The absolute magnitude of the changes in dimension is relatively unimportant to this discussion, but the proportional changes enable us to understand the operation of this system. In the particular case diagrammed in Figures $13 \mathrm{a}, \mathrm{b}$ the swimming muscle contracts to $56 \%$ of its original length. The bell thickens by $36 \%$ perradially, $34 \%$ interradially, and $51 \%$ adradially. At the adradius, however, this deformation is unequally distributed between the bell mesoglea (23\% linear increase) and the joint mesoglea (200\% increase). Thus it is the high deformability of the joint mesoglea distributed along eight meridians that is responsible for the essentially octamerous symmetry of the contracted bell. The actual deformation is compared with that which would occur in a hypothetical bell without joint mesoglea (Fig. 13c) during a contraction of the same magnitude. A diagram of such a bell is easily constructed, since it has been established that there is no longitudinal displacement of mesoglea, so that assuming no increase in volume, the crosssectional area of the bell at a given level remains the same during contraction. When the muscular sheet contracts it effectively pulls the per-and interradii toward each other, causing the low triangular areas of deformable joint mesoglea in between to be tangentially compressed, resulting in high narrow triangular areas. At the same time the 

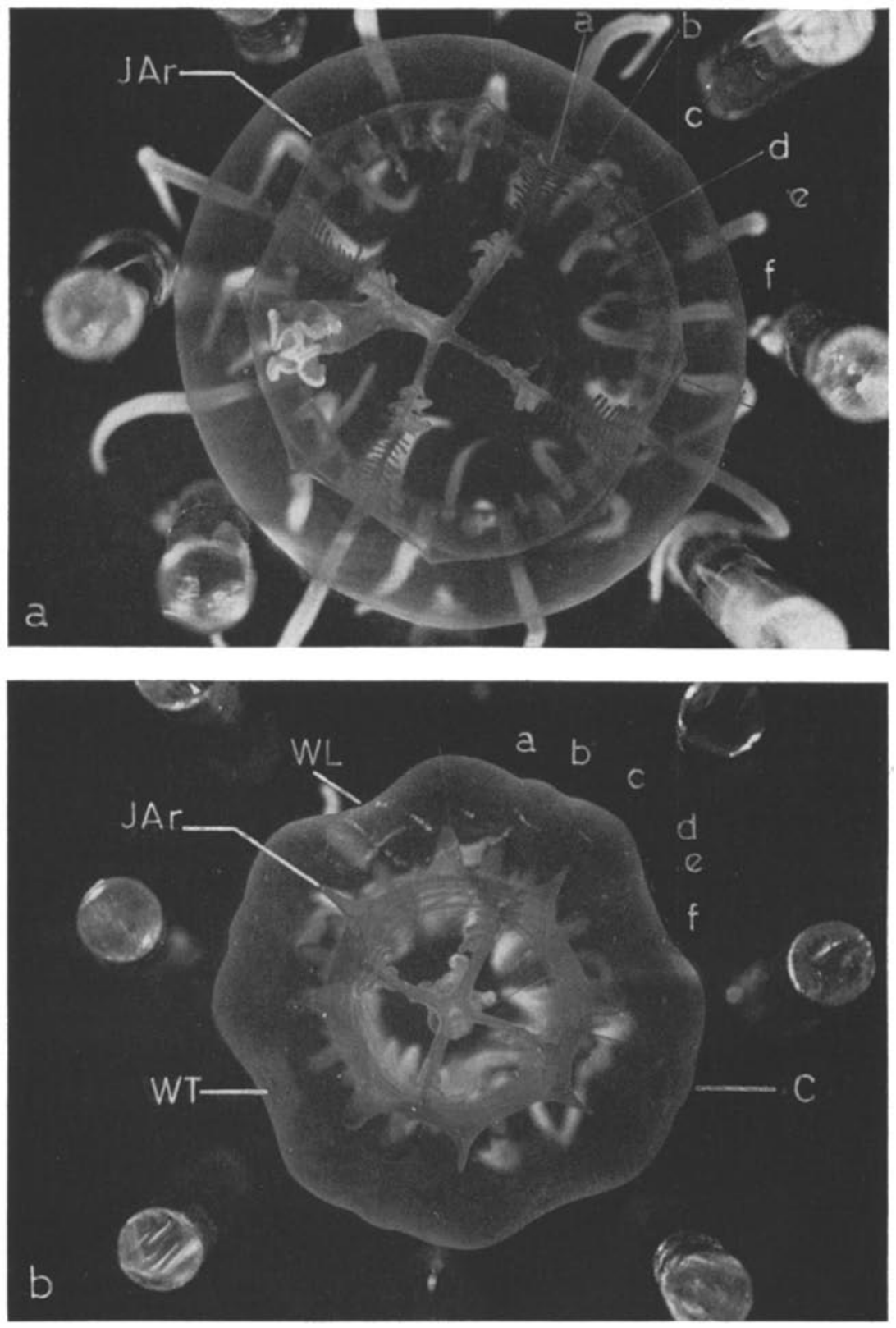

Fig. 12: Axial view of Polyorchis montereyensis in relaxed (a) and contracted (b) conditions, to the same scale. Fine glass needles inserted in a horizontal row at midbell serve as reference points to determine localized deformation (see text). C contracted outline; JAr adradial joint; WL longitudinal wrinkle; WT transverse wrinkle 
vertex of the adradial joint is securely anchored to the bell mesoglea by the convergence of the radial mesogleal fibers on an especially thick region of the basement membrane of the gastrodermal lamella (Figs. 9a, b). The distal portion of the adradial joint is so compressed that the gastrodermal lamella on the two sides of the vertex is pulled virtually into contact (Figs. 12,13). Thus, although the swimming muscle sheet undergoes a $44 \%$ decrease in circumference at midbell, the circumference of the inner surface of the bell mesoglea decreases by only $14 \%$ (Fig. 13). The appropriateness of the term "joint" is now realized: this wedge-shaped region of highly deformable jelly serves as a fulcrum around which the main bell mesoglea is bent by the musculature anchored on either side of the joint.

In order to determine the actual magnitude of the bending at different points on the circumference, fine glass needles were inserted perpendicularly through the bell wall at the midbell region (Fig. 12) and the animals were photographed as before. The changes in angles between different glass rods during contraction were then measured. At the adradius (Fig. 12) there is a $6^{\circ}$ increase in the angle between rods " $c$ " and "d". Interradially there is an $8^{\circ}$ decrease between rods " $e$ " and " $f$ ". Between rods "a" and " $b$ " at the perradius there is a $5^{\circ}$ decrease. In terms of actual arc length, there is a very slight decrease in the adradial exumbrella. At the interradius the arc length decreases by about $30 \%$, whereas perradially the decrease in arc length is about $15 \%$. The relatively great decrease at the interradii is accompanied by fine longitudinal wrinkles (Figs. 11b, 12b).

Thickening of the bell on contraction is slightly greater at the perradii than at the interradii. In order to determine the cause of this difference in thickening, seven individuals were examined. In six of these the vertices of the adradial joints were farther apart interradially than perradially, thus allowing a greater amount of bending at the interradii, i.e., less thickening. In the seventh case, however, the perradial distances between joints were greater, but thickening was still greater perradially. The spacing of the adradial joints in a single individual therefore does not completely explain the greater bending at the interradius. However, in comparing perradial sectors of different medusae, the relatively wider a perradial sector is, the greater is the inward bending of the exumbrellar here, hence less thickening. Thus the spacing of the joints appears to play some role in determining the amount of perradial thickening.

The deformation of the bell is brought about by the contraction of the swimming muscle. The geometry of the deformation however, is dependent upon the distribution of elasticity in the bell. The eight meridional joints, as has been seen, provide areas of mesogleal deformability much greater than that of the surrounding bell mesoglea. The concentration of mesogleal fibers is another parameter of differential elasticity: the greater the concentration of radial fibers the less deformable the mesoglea of that region. This was determined by comparing deformation of the bell in various regions with the concentration of fibers. While it is possible that differences might exist in the elastic properties of the matrix of the bell mesoglea along different radii, evidence for this is lacking and such hypothetical differences need not be invoked to explain the observed deformation. Around the circumference of the bell, at any given level the density of the radial fibers which anchor the exumbrella to the supporting lamella is slightly greater in the interradial than in the perradial areas (Table 1); as a consequence 
during contraction the interradial areas do not thicken quite as much as do the perradial areas. Where the fibers converge on the adradial joints, considerably increasing the fiber density there, thickening of the bell is considerably less than in the surrounding region where the joint mesoglea is also acting in series with the bell mesoglea.

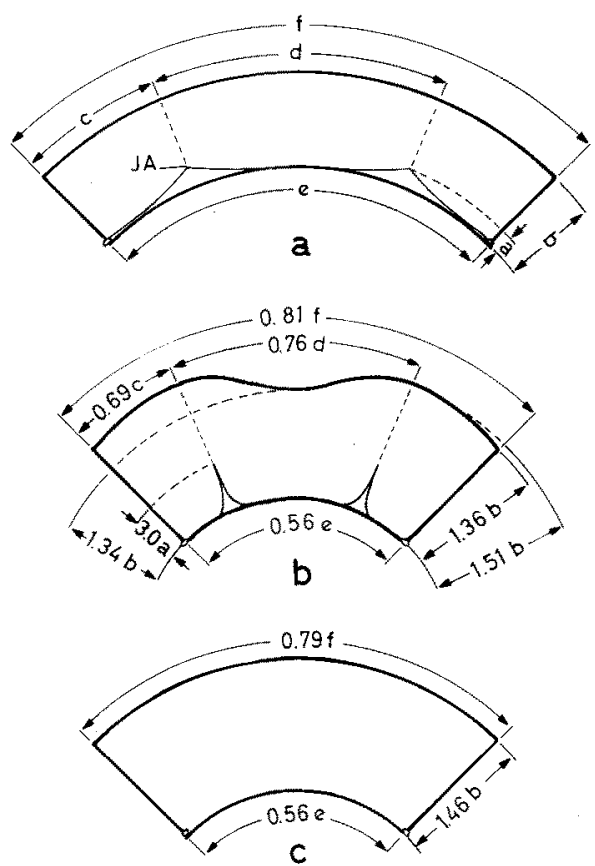

Fig. 13: Cross-sectional diagram of one quadrant at midbell in Polyorchis montereyensis. The dimensions of $13 a$ and $13 b$ were obtained directly from Figure 12. Figure $13 c$ was constructed so that its cross-sectional area remained the same as the uncontracted bell (13a) with a decrease in the length of the subumbrella equal to that of $13 b .(a)$ Relaxed condition; $(b)$ contracted condition; $(c)$ contracted condition, hypothetical, without joints. a height of adradial joint, $b$ thickness of bell, $c$ length of exumbrellar arc between ad-and perradius, $d$ length of exumbrellar arc between adradii, e length of subumbrellar arc between perradi, $f$ length of exumbrellar arc between perradii (all in relaxed condition). $J A$ adradial joint

On the basis of the inverse relationship between fiber density and deformability of the mesoglea, it is likely that one role of these fibers is in providing radially oriented tensile strength to the bell. These fibers are elastic in their behavior, though there is some conflicting evidence as to their chemical nature (Bourclon \& VANDERMEerssche 1957, Chapman 1953a, 1959; discussion in this paper). Each fiber seems to be acting as a spring with a given elastic constant " $k$ ". The force needed to deform the mesoglea a given amount is proportional to the number of these essentially identical springs (i.e., the fibers). Each fiber is straight in both the relaxed and contracted conditionst, in-

* In fixed material shrinkage of the mesogleal matrix without equivalent shrinkage of the fibers leads to their assuming an irregular helical conformation. 
dicating that it must undergo a significant amount of stretch when extended. The repeated branching of the fibers toward the subumbrella would serve to distribute the tensile force over a broader area on the inner surface of the bell mesoglea where anchorage to the underlying supporting and gastrodermal lamellae is necessary. At their exumbrellar ends the fibers are continuous with the loose subepithelial fiber plexus; this serves to anchor these fibers to the relatively soft outer region of the bell, where the plexus can act as a shock absorber. This exumbrellar soft region allows for the longitudinal wrinkling on contraction as seen in Figures 11 and 12, and also for the great exumbrellar compression occurring in the interradii (Fig. 12).

The preceding examination of the deformation of the bell enables us now to discuss the stresses which are generated within the deformed mesoglea. As the swimming muscle contracts and deforms the bell mesoglea, the forces generated in the latter oppose the action of the muscle.

To illustrate the action and significance of the joint system, consider first the stresses that would be generated in a simplified hypothetical $P$. montereyensis such as that in Figure 13c. In the uncontracted condition the dimensions of this bell are identical to those of the actual bell with which it will be compared. Elastic properties are identical around the bell, since there is no joint mesoglea. As the swimming muscle contracts it compresses the bell in the circular direction. This causes a radial thickening which is opposed by the tensile strength of the radial mesogleal fibers. Thus there are two components of the strain (hence the stress) generated in the bell by the contracting muscle: a circular compressional component and a radial tensile component (CHAPMAN 1958). The compressional deformation is $44 \%$ at the subumbrellar surface but only $21 \%$ at the exumbrellar surface. Thus the compressional stresses generated are about twice as great at the inner as at the outer surface. The compressional force seems to be the primary one involved in opposing the muscular contraction since it is oriented circularly, the same direction as the force bringing about the deformation. If the compressional force (stress) is proportional to the compressional deformation (strain) and the bell has a circular elastic constant " $K_{c}$ ", then the compressional force generated can be represented as $-44 \mathrm{~K}_{\mathrm{c}}$ at the subumbrellar surface and $-21 \mathrm{~K}_{\mathrm{e}}$ at the exumbrella. The radial tensile component, based on a $46 \%$ thickening of the bell would be $46 \mathrm{~K}_{\mathrm{r}}$, where $\mathrm{K}_{\mathrm{r}}$ is the radial elastic constant.

In contrast to this simplified circularly symmetrical system, the actual bell has a series of longitudinal joints around its circumference. As in the hypothetical example just presented, whose relative dimensions were based on the case now being discussed (Fig. 13), the swimming muscle undergoes a $44 \%$ decrease in length (= circumference). However, instead of causing a $44 \%$ compression of the bell mesoglea at the subumbrellar surface, the bell mesoglea is compressed by only $14 \%$ at its inner surface. This is because the bell mesoglea is bent together and outward at the joints as the perand interradial lines of muscle anchorage are pulled together (Figs. 12, 13). The exumbrellar surface undergoes a $19 \%$ decrease, slightly less than in the hypothetical case, distributed unequally between per-, inter- and adradii. The compressional force in the bell mesoglea at its inner surface would be $-14 \mathrm{~K}_{6}$, about one-third of the compressional force at the inner surface of the hypothetical bell. At the exumbrella the average compressional force would be $-19 \mathrm{~K}_{\mathrm{e}}$ or only slightly less than in the case of 
the jointless medusa. However, it will be remembered from previous discussion that circular compression is relatively great in the interradii and relatively slight in the adradii, as was determined by measuring the distances between glass needles inserted horizontally at midbell. Considering the radial components of the forces generated in the bell mesoglea, at the interradius there is a $34 \%$ elongation, at the perradius a $36 \%$ increase and at the adradius a $16 \%$ increase. Thus the radial stresses generated are $34 \mathrm{~K}_{\mathrm{r}}, 36 \mathrm{~K}_{\mathrm{r}}$ and $16 \mathrm{~K}_{\mathrm{r}}$ respectively. This compares to a stress of $46 \mathrm{~K}_{\mathrm{r}}$ in the hypothetical bell.

The stresses generated have been assumed to be proportional to the relative compression or extension in the deformed bell. Another assumption that has been made in this analysis is that the joint mesoglea has played a more or less passive role, that the change in its configuration is due to forces generated by the swimming muscle and bell

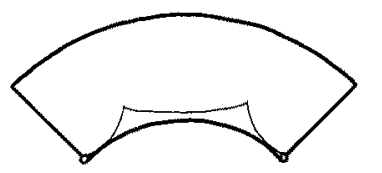

a
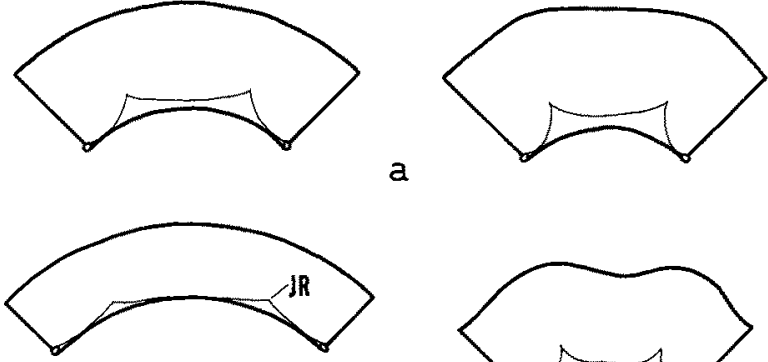

$b$
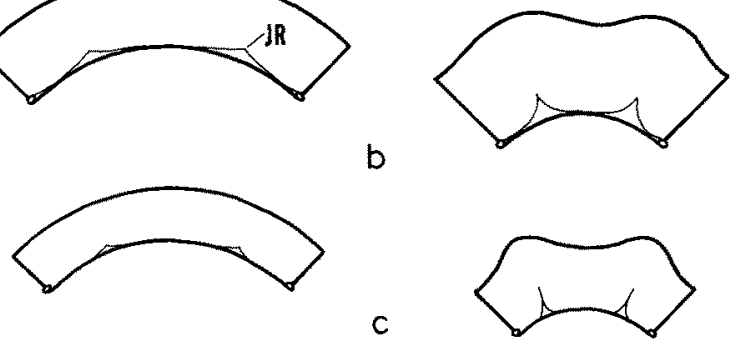

Fig. 14: Diagrams of cross-sections of the bell of Polyorchis montereyensis at three levels, in relaxed (left) and contracted (right) conditions. (a) Section just below the subumbrellar summit; (b) Section about midbell; (c) Section near the margin. $J R$ radial joint

mesoglea working on a soft, easily deformed but non-flowing substance (i.e., the joint mesoglea) whose cross-sectional area remains constant during contraction. There must be a radial tensile force generated in this mesoglea, as well as a circular compressional one, but the considerably greater proportional stretch (12 times as much as the adradial bell mesoglea) of this region is an indication of its much lower elastic constant, hence the much smaller force required to deform this mesoglea a certain amount.

The foregoing comparison between the deformation of the actual bell and a hypothetical one lacking joints, and the respective forces created in the mesoglea in opposition to the contractile force of the swimming muscle, has shown that the joints enable an animal to make a contraction of a given magnitude with significantly less force than would be required without them.

The morphology and deformation of the bell as seen in axial (cross-sectional) view are basically the same at all levels of the subumbrella except near the summit, where 
the gastrodermal lamella is no longer in direct contact with the basement membrane of the subumbrellar epitheliomuscular sheet, and near the margin of the bell where contact is virtually continuous around the perimeter (Fig. 14). At maximum contraction the greatest decrease of the subumbrellar muscle, both absolutely and relative to its original length is at midbell or somewhat marginal of this. The absolute and proportional decrease is least at the summit.

Above midbell the exumbrellar outline of the per- and interradial sectors is flatsided rather than scalloped as at midbell (Fig. 14). Toward the apex the joints are more pronounced in the relaxed medusa, but do not elongate proportionally as much as at midbell on contraction due to the fact that deformation is not as great at this level of the bell. Toward the margin the scalloped outline of the exumbrella is even more pronounced on contraction than at midbell, the adradial bulges being set off more sharply from the per- and interradial areas (Fig. 14). In this marginal region the exumbrellar troughs occupy larger sectors of the circumference than higher up on the bell. The adradial joints undergo a relatively greater deformation here than higher up the bell, but the bell mesoglea increases proportionally less in thickness. Hence, progressing from upper to lower regions of the bell, thickening becomes a less important, and folding around the joints a more important factor in the deformation of the bell on contraction. This shift in the relative roles of the two types of deformation is a function of the thickness of the bell mesoglea on the one hand and the concentration of the mesogleal fibers on the other, which was earlier shown to be proportional to tensional force generated in the mesoglea by a given muscular force.

The fourth component of bell deformation, flexion around the apical joint (Fig. 11) was determined by photographing the relaxed and contracted animal in lateral view with a longitudinal row of fine glass needles inserted in the bell then measuring the changes in angle between the needles. The angle between needles in the lateral bell wall (Fig. 11, nos. 1-4) decreases slightly on contraction due to a longitudinal straightening of the curvature here. From the latitude of the circular apical joint, however, to a latitude directly above it, the angle between successive needles increases. In this roughly rightangled wedge there is a $9^{\circ}$ increase on the exumbrellar side of the bell. The exumbrella of this region lengthens by about $6 \%$. The bell mesoglea between the circular apical joint and the exumbrellar surface undergoes virtually no thickening, but the joint itself becomes elongated at about needle no. 6 , due to a very distinct flexing of the exumbrella there. Thus the apical joint is operating much like the adradial joints: a wedge-shaped area of very deformable joint mesoglea is acting as a fulcrum between the apical mass and the lateral bell wall which is bent around it. As in the case of the longitudinal joints, there is a convergence of the radial fibers of the bell mesoglea on the circular joint, anchoring its vertex to the bell mesoglea (Fig. 3). The bell apex is devoid of radial fibers but has a loosely organized fiber plexus; this region is softer than the lateral bell wall. Straight radial fibers are present only in those regions of the bell that are deformed on contraction (Figs. 1, 17). The region of the apical plexus remains essentially undeformed throughout the contraction. The straight fibers which descend onto the peduncle virtually terminate at the junction of the gastrodermal lamella and the subumbrellar epidermis; i.e., where both the apical joint and the swimming muscle terminate (Fig. 3). The correspondence of the distri- 
bution of the radial fibers with the regions of deformation support the idea that these fibers play an important role in transmitting the tensile forces generated during deformation, while at the same time serving to anchor the underlying regions to the bell mesoglea, especially at the joint vertices.
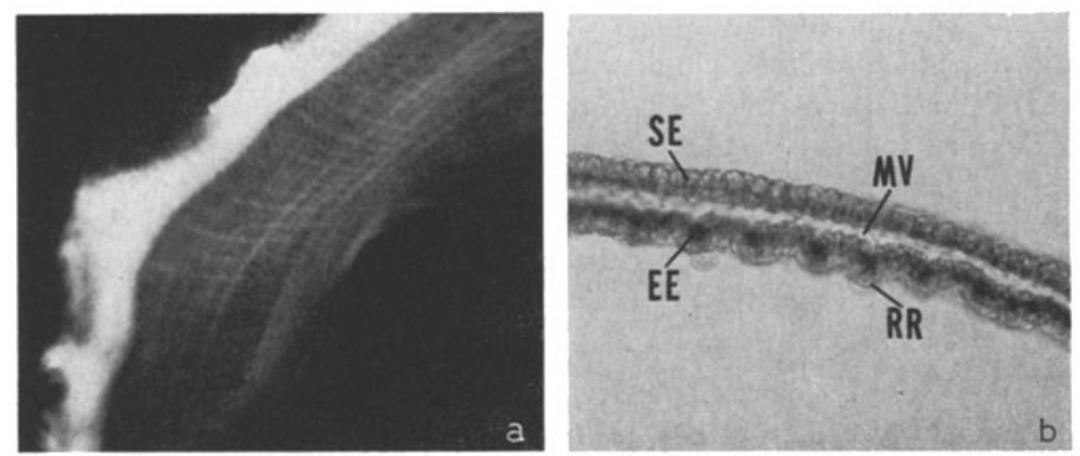

Fig. 15: System of ridges in the velar mesoglea of Polyorchis montereyensis (unstained HCHO fixed material). (a) Oblique view from the exumbrellar surface of a sector of the velum, photographed through the dissecting scope. (b) Hand-cut vertical radial section through the velum. $E E$ subumbrellar epidermis; $M V$ velar mesoglea; $R R$ circular ridge; $S E$ exumbrellar epidermis
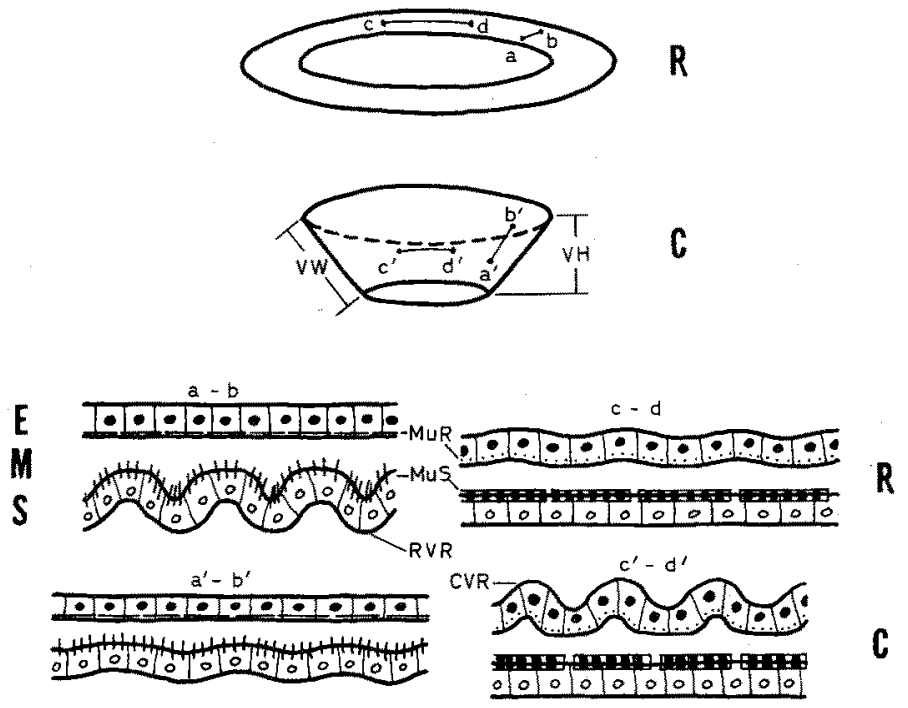

Fig. 16: Mechanism of deformation of the velum on contraction. Above: Diagram of relaxed and contracted velum. Below: Circular and radial sections through the velum, showing the relationships between the circular and radial mesogleal ridges. Radial section on left (indicated in 16a) and circular section on right. In each case the upper figure is relaxed and the lower is contracted. $E$ exumbrellar epidermis; $M$ velar mesoglea; $S$ subumbrellar epidermis; $R$ relaxed; $C$ contracted; $M u R$ velar radial muscle; $M u S$ velar circular muscle; $V H$ velar height; $V W$ velar width; $R V R$ circulat velar ridge; $C V R$ radial velar ridge 
The velum is anchored to the inside margin of the bell by a thin region of relatively dense mesoglea which stains as deeply as the basement membrane of the subumbrellar epidermis, and is indeed continuous with the latter (Fig. 7). As the swimming muscle of the subumbrella and velum contract, water being expelled from the subumbrellar cavity forces the velum outward from its shelf-like configuration to the form of a truncated cone (Figs. 16a, 17, 18). This action is facilitated by the constriction at the base of the velum, which though very thin provides secure anchorage of the velum to the bell because of its high concentration of collagenous material. The action of the contracting circular muscle of the velum is antagonized by the pressure of the water forced out of the bell cavity, and also by the mesogleal skeleton of the velum. As the velum contracts, it decreases in circumference, but increases in width, probably due to the force exerted by the expelled water. The mesogleal skeleton of the velum is only about as thick as either of the epitheliomuscular layers anchored to it, and in relation to the length or width of the organ as a whole is very thin (Figs. 4, 15b). Yet when it is reduced in circumference it retains its smooth conformation. Two factors are responsible for this. On closer inspection of velums fixed in relaxed and contracted conditions and cut into thin tangential sections $(0.1-0.2 \mathrm{~mm}$ ), it is seen (Fig. 16b) that the low radial ribs of mesoglea that are located on the side of the skeleton opposite that of the contracting muscle (i.e., on the exumbrella) are exaggerated on contraction. That is, when the circular muscle fibers of the subumbrellar side of the velum contract, they compress the mesoglea in the circular direction so that the amplitude of the numerous radial folds is increased, providing a very uniform means of displacing a thin flexible layer of mesoglea without weakening its effectiveness in uniformly reducing the aperture of the bell cavity. Due to the extreme thinness of the mesoglea however, this system could probably not operate without the simultaneous existence of the hydrostatic pressure created by contraction of the bell on a confined volume of water. It is this second factor which mainly supports the thin velum; the existence of the numerous folds serves to maintain the uniformity and smoothness of conformation of the velum. As will be seen subsequently, the radial muscle fibers of the exumbrellar side of the velum are sometimes brought into action. Even in cases where these do not contract, the reduction in width of the velum during recovery must be effected smoothly and uniformly, and in fact the series of circular ridges in the mesoglea of the subumbrellar side of the velum act in the same capacity during recovery of the velum as do the radial exumbrellar ridges during contraction. It should be noted that in both cases the ridges are located on the side of the velar skeleton opposite the muscle whose action raises them. These ridges also serve to amplify the surface area available for attachment of the circular muscle fibers; the radial ridges serve the same function for the radial muscle fibers.

At the termination of the contraction phase of the swimming cycle the potential energy generated within the bell and velar mesoglea is at a maximum. The bell is compressed in the circular direction and stretched radially and is bent around the apical joint; the velum is compressed circularly and stretched radially. Now as the swimming muscle begins to relax, the mesogleal forces become the active agents in effecting the recovery of the bell to its resting form. More will be said of the recovery in subsequent paragraphs. 


\section{Morphodynamics of swimming}

In 39 cases examined, using 13 different medusae, the average circumference of the subumbrella decreased by $37 \%$ during contraction, ranging from a $25 \%$ reduction to one of $52 \%$ (Table 2). The average percent reduction of the subumbrellar circumference is roughly inversely proportional to the size of the animal (Table 2), larger animals tending to contract less fully than smaller ones. However, for a given animal, measurements show there can be at least a $25 \%$ difference in the magnitude of contraction.

As the subumbrellar muscle contracts, it does not do so uniformly at all levels of the bell. The sequence of shape changes taking place in lateral profile of a represent-

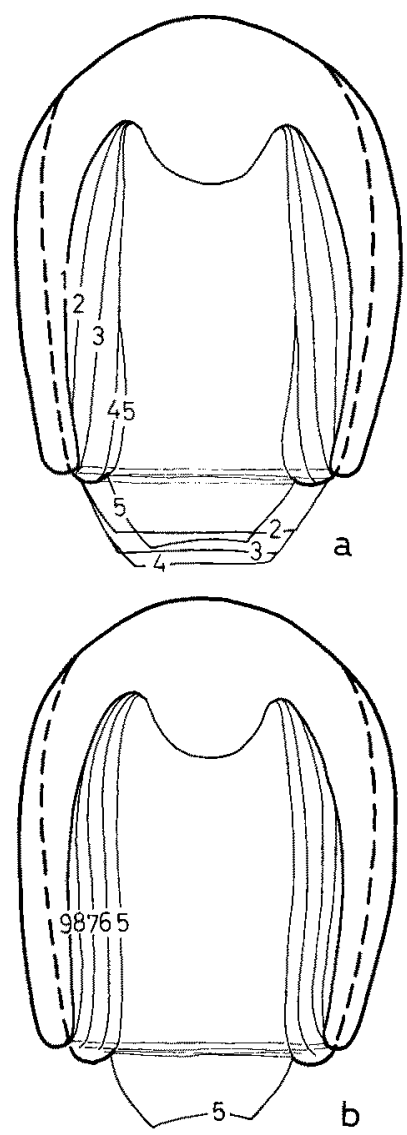

Fig. 17

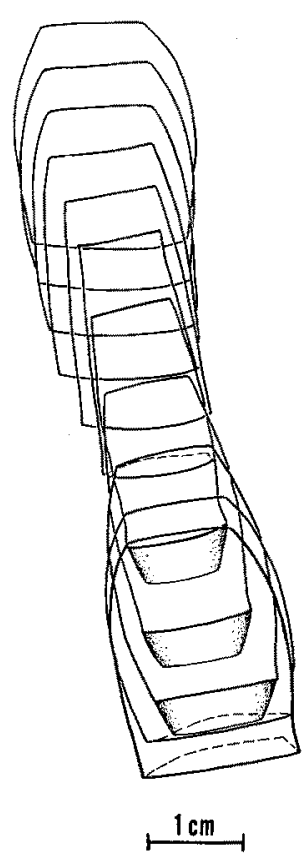

Fig. 18

Fig. 17: Contraction (a) and recovery (b) profiles of Polyorchis montereyensis during a single contraction cycle, traced from cinematographic sequences. Numbers indicate successive stages of the subumbrella and velum; time interval equals $1 / 12 \mathrm{sec}$

Fig. 18: Contraction and recovery sequence of subumbrella in lateral view, showing actual change in position; traced from cinematographic sequences. Time interval equals $1 / 16 \mathrm{sec}$ 
Table 2

Swimming statistics of Polyorchis montereyensis. A: Individual \#. B: Bell height (mm). C: Average relaxed circumference of subumbrella $(\mathrm{cm})$. D: Average contracted circumference of subumbrella $(\mathrm{cm})$. E: $\%$ decrease in average subumbrellar circumference on contraction. F: Average $\%$ decrease for all sequences of one individual. G: Average $\%$ decrease for all sequences of one size class. H: Initial velocity $(\mathrm{mm} / \mathrm{sec})$. J: Maximum velocity $(\mathrm{mm} / \mathrm{sec})$. K: Velocity gained $(\mathrm{mm} / \mathrm{sec})$

\begin{tabular}{|c|c|c|c|c|c|c|c|c|c|}
\hline $\mathrm{A}$ & B & C & D & $E$ & F & $\mathrm{G}$ & $\mathrm{H}^{*}$ & $\mathrm{J*}$ & $\mathrm{K}^{*}$ \\
\hline \multirow[t]{4}{*}{1} & 40 & 7.23 & 5.04 & 30 & 28 & 28 & 0 & 36 & 36 \\
\hline & & 6.98 & 5.02 & 28 & & & 4 & 42 & 38 \\
\hline & & 7.08 & 5.18 & 27 & & & 16 & 50 & 34 \\
\hline & & 7.10 & 5.29 & 26 & & & 18 & 39 & 21 \\
\hline \multirow[t]{2}{*}{2.} & 30 & 5.63 & 3.46 & 39 & 39 & 34 & -7 & 18 & 25 \\
\hline & & 5.63 & 3.46 & 39 & & & 0 & 25 & 25 \\
\hline \multirow[t]{3}{*}{3} & 28 & 5.13 & 3.23 & 37 & 36.5 & & -6 & 25 & 31 \\
\hline & & 5.03 & 3.22 & 36 & & & 22 & 58 & 36 \\
\hline & & & & & & & 31 & 71 & 40 \\
\hline 4 & 26 & 4.83 & 3.60 & 25 & 25 & & 13 & 31 & 18 \\
\hline \multirow[t]{8}{*}{5} & 16 & 2.77 & 1.65 & 40 & 35 & 36 & 0 & 29 & 29 \\
\hline & & 2.72 & 1.62 & 40 & & & 23 & 49 & 26 \\
\hline & & 2.65 & 1.66 & 37 & & & 24 & 51 & 27 \\
\hline & & 2.68 & 1.78 & 34 & & & 24 & 63 & 39 \\
\hline & & 2.70 & 1.82 & 33 & & & 25 & 53 & 28 \\
\hline & & 2.66 & 1.80 & 32 & & & 27 & 54 & 27 \\
\hline & & 2.73 & 1.98 & 28 & & & 27 & 55 & 28 \\
\hline & & & & & & & 29 & 64 & 35 \\
\hline \multirow[t]{2}{*}{6} & 15 & 2.85 & 1.75 & 39 & 38.5 & & 25 & 56 & 31 \\
\hline & & 2.89 & 1.78 & 38 & & & 34 & 58 & 24 \\
\hline \multirow[t]{3}{*}{7} & 15 & 2.62 & 1.42 & 46 & 41 & & 17 & 49 & 32 \\
\hline & & 2.65 & 1.54 & 42 & & & 20 & 59 & 39 \\
\hline & & 2.62 & 1.71 & 35 & & & 26 & 70 & 44 \\
\hline \multirow[t]{3}{*}{8} & 14 & 2.61 & 1.58 & 39 & 35 & & 10 & 50 & 40 \\
\hline & & 2.33 & 1.53 & 34 & & & 21 & 60 & 39 \\
\hline & & 2.36 & 1.62 & 31 & & & & & \\
\hline \multirow[t]{4}{*}{9} & 8 & 1.46 & 0.91 & 38 & 33 & 41 & 13 & 43 & 30 \\
\hline & & 1.57 & 1.09 & 38 & & & 16 & 42 & 26 \\
\hline & & 1.53 & 1.08 & 29 & & & 16 & 46 & 30 \\
\hline & & & & & & & 20 & 46 & 26 \\
\hline \multirow[t]{2}{*}{10} & 7 & 1.27 & 0.66 & 48 & 46.5 & & 9 & 34 & 25 \\
\hline & & 1.21 & 0.66 & 45 & & & 14 & 42 & 28 \\
\hline \multirow[t]{6}{*}{11} & 7 & 1.09 & 0.52 & 52 & 44 & & 2 & 35 & 33 \\
\hline & & 1.09 & 0.58 & 47 & & & 8 & 35 & 27 \\
\hline & & 1.07 & 0.57 & 47 & & & 11 & 29 & 18 \\
\hline & & 1.25 & 0.78 & 38 & & & 13 & 37 & 24 \\
\hline & & 1.07 & 0.60 & 44 & & & 20 & 44 & 24 \\
\hline & & 1.10 & 0.68 & 38 & & & 20 & 50 & 30 \\
\hline \multirow[t]{3}{*}{12} & 7 & 1.25 & 0.73 & 42 & 41 & & 15 & 50 & 35 \\
\hline & & 1.12 & 0.66 & 41 & & & & & \\
\hline & & 1.24 & 0.76 & 39 & & & & & \\
\hline
\end{tabular}

ative animal is shown in Figure 17. The decrease in diameter at each level of the bell can be measured and the fraction of a full contraction undergone at each level during each interval can be calculated. For simplicity the contraction phase is divided into three successive periods, each lasting $0.12 \mathrm{sec}$. During the first period the region near 
the subumbrellar summit undergoes half of its total contraction. Near the margin the bell undergoes only about a quarter of its total decrease during this first interval. During the second period the contraction increments are more or less equal up and down the bell. In the last period of contraction the situation is the reverse of the first: now the greatest proportional decrease in subumbrellar diameter is at the margin, becoming progressively less toward the summit. In some instances the upper region of the bell began contraction before any occurred in the marginal third of the bell, or even while expansion was still occurring marginally. In a few instances both apical and marginal regions began the contraction strongly. The former, more general case is suggestive of a wave of contraction passing from apex to margin, but it is a wave only in the strength of the contraction in most instances. The contraction, averaged over all levels of the subumbrella begins slowly, increases through a grand period during which the average rate of contraction is more or less constant, then decreases in rate toward maximum reduction of the subumbrellar cavity (Fig. 20). The actual duration of the contraction is largely a function of the size of the individual and increases roughly as the square root of the subumbrellar circumference (Fig. 20). For a large medusa about $40 \mathrm{~mm}$ high, the duration of the contraction is about $0.4-0.5 \mathrm{sec}$. For a small medusa, about $7 \mathrm{~mm}$ high, contraction lasts from $0.15-0.2 \mathrm{sec}$.

The recovery phase of the swimming cycle takes about $30 \%$ longer than contraction, but ranges from the same duration as the contraction to $50 \%$ longer. As in the case of contraction, recovery begins slowly, becomes more rapid, then slows down as the fully relaxed form is approached. Just as the contraction does not always end simultaneously at all levels of the bell, the recovery may begin at one level while contraction is still occurring at another. Since the bell of a single individual recovers at different rates in different cycles, it seems that the swimming muscle, by relaxing at different rates, may be affecting the recovery rate: otherwise, it would be expected that the elastic properties of the bell, being constant, would effect recovery at about the same rate in all instances for a particular individual.

In $P$. montereyensis the contraction of the bell begins slowly (Fig. 20). The circular swimming muscle of the subumbrella and that of the velum begin contracting essentially simultaneously. As the subumbrellar cavity narrows, the water which is discharged forces the velum outward (Fig. 17a) from its original shelflike position, so that by the beginning of the grand period of the contraction the velum is about $75 \%$ extended (i.e., it achieves $75 \%$ of its maximum height). During this initial phase of the contraction very little water actually exits through the velar aperture. Considering the mass of water enclosed within the subumbrellar cavity and velum to be part of the mass of the system, there is virtually no acceleration of the center of mass of the bell*during this early part of the contraction, although there is an apparent increase in

* The center of mass of the bell was determined by cutring the bell horizontally by trial and error until portions of equal weight were obtained. The position of this cut was between one-half and one-third the distance from the margin to the bell apex in several bells so treated. The center of mass of the water in the bell cavity was determined by summing the volumes of the horizontal segments into which the bell was divided for other analyses. The two points were averaged and the center of mass of the system was located about two-fifths of the distance from the margin to the apex. 

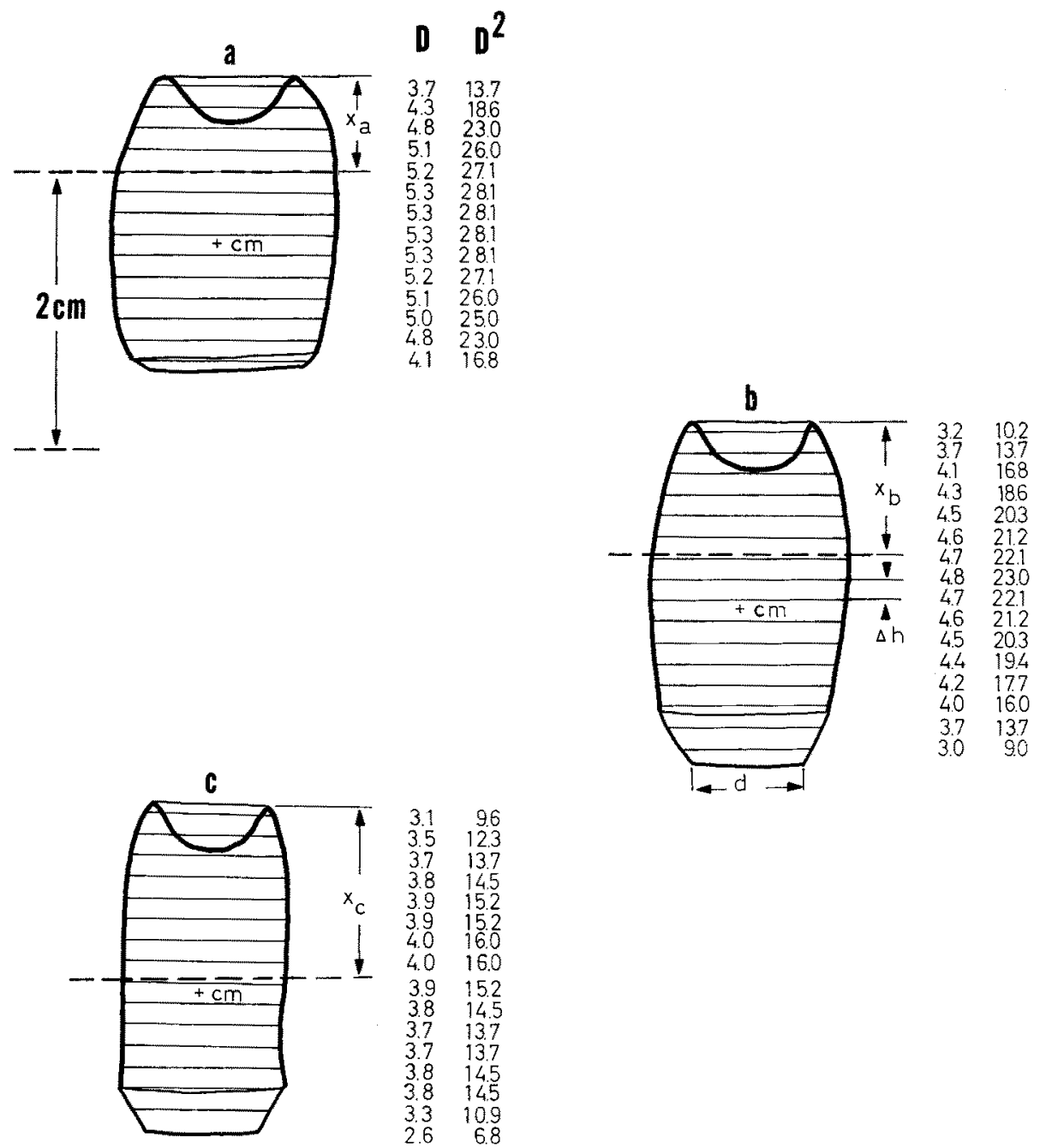

$\begin{array}{rr}3.1 & 9.6 \\ 3.5 & 12.3 \\ 3.7 & 13.7 \\ 3.8 & 14.5 \\ 3.9 & 15.2 \\ 3.9 & 15.2 \\ 4.0 & 16.0 \\ 4.0 & 160 \\ 3.9 & 15.2 \\ 3.8 & 14.5 \\ 3.7 & 137 \\ 3.7 & 13.7 \\ 3.8 & 14.5 \\ 3.8 & 14.5 \\ 3.3 & 10.9 \\ 2.6 & 6.8\end{array}$

Fig. 19: Method of analyzing locomotion in Polyorchis montereyensis. The outline of the subumbrellar cavity (and velum when possible) is traced from each successive projected frame of a $16 \mathrm{~mm}$ movie sequence of a swimming medusa $(a, b, c)$. This outline is divided into about 12 to 14 segments by equally spaced horizontal lines (diameters). These are measured, the true scale being provided by the grid etched into the back of the photographic chamber. The relative position of the bell with respect to the fixed grid can also be measured for each successive frame. With these few measurements and the known time interval between successive frames, all the parameters of locomotion listed in the figure can be calculated. D diameter of subumbrellar cavity at each level, $\mathrm{n}$ number of diameters into which the subumbrellar cavity is divided, $\Delta \mathrm{h}$ distance between successive diameters, $\mathrm{V}$ volume of subumbrellar cavity (including velar portion), d diameter of velar aperture, $A$ area of velar aperture, $S_{w}$ velocity of expelled water, $S_{b}$ velocity of bell, $\sigma$ specific gravity of seawater, $t$ time interval between successive frames, $\mathrm{M}_{\mathrm{w}}$ mass of expelled water, $\mathrm{M}_{\mathrm{b}}$ mass of bell and enclosed water, $\Delta \mathrm{x}$ change in position of c.m. between successive frames, $U_{w}$ momentum of expelled water, $U_{b}$ momentum of bell, c.m. center of mass 
velocity when the relative position of the bell apex alone is measured, due to slight elongation of the bell. As the grand period begins, marked by an increased rate of muscular contraction (Fig. 20), the velar aperture continues to narrow (Fig. 17a) and is protruded to its fullest extent. This phase is the period of acceleration of the center

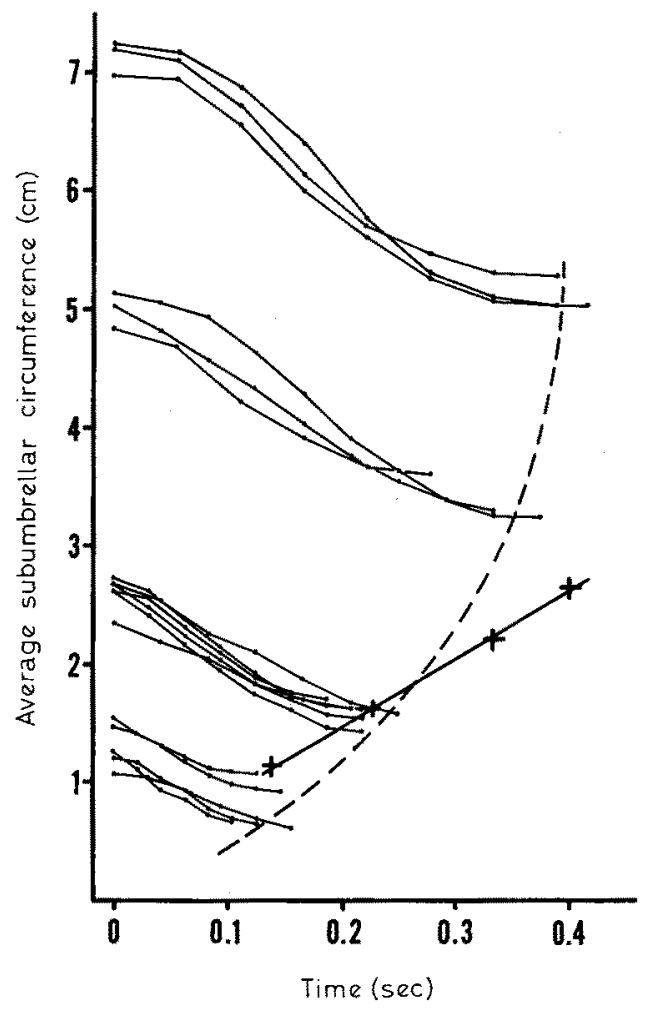

Fig. 20: Rates of reduction of the average subumbrellar circumference of the bells of medusae (Polyorchis montereyensis) in different size classes (Table 2). The heavy dashed line represents the average duration of contraction as a function of average subumbrellar circumference. The duration of the contraction increases approximately as the square root of the subumbrellar circumference (or height) of the animal. The straight, heavy line represents the square root of the average subumbrellar circumference of the bell for each size class as a function of the average duration of the contraction for each size class

of mass of the bell, during which maximum velocity is achieved. The end of the grand period is marked by maximum acceleration of the bell. After this, the bell continues to contract but at a slower rate. The velar aperture continues to constrict, but the amount to which it is protruded decreases (Fig. 17a). The velocity of the bell decreases sharply till after the beginning of the recovery then tapers off very slowly. Just before the end of the contraction the diameter of the velar aperture decreases quite sharply as the protruded velum continues to decrease in height. A sudden inward flip of the velum marks the beginning of the recovery; it accompanies the sudden insurge of water as the 
subumbrellar cavity initially expands. During recovery the diameter of the bell in most cases increases rather uniformly and the bell proceeds with very slightly diminishing velocity (Fig. 18).

By subdividing the contraction phase into a number of equal time intervals, the elementary dynamics of this system can be analyzed (Fig. 19). During the initial stage of the contraction virtually no water is expelled from the confines of the bell and velum. There is no change in the velocity of the system during this period. As the strength of the contraction increases however, water is expelled through the velar aperture at a velocity: $\frac{A \cdot d V}{d t}$, where $d V$ is the increment of expelled water. $A$ is the area of the velar aperture, and $\mathrm{dt}$ is the time interval (Fig. 19). Each increment of expelled water has a mass $\mathrm{m}$. Therefore the momentum of each increment of expelled water is: $\frac{m \cdot d V}{A \cdot d t}$. In an ideal system (one without friction), a momentum equivalent in magnitude to that of each increment of expelled water, but oppositely directed, should be imparted to the bell and its contained mass of water. Thus, in an ideal system, momentum of the bell should increase to the end of the contraction. Since the mass of the bell plus water is constantly decreasing during contraction due to the expulsion of water, the velocity of the bell should increase at an even greater rate than the momentum. The actual relationship between momentum, theoretical momentum, velocity and the rate of acceleration in a representative medusa are presented in Table 3 . Notice that although the momentum of expelled water increases to the end of the contraction, the momentum of the medusa increases rapidly initially, but then declines at a point when the strength of contraction and the momentum of each increment of expelled water lessen. Increasing friction between the medusa and the surrounding water is probably responsible for this. Though momentum and velocity increase roughly at the same initial rate, toward the end of the contraction momentum decreases at a greater rate, as would be expected since the mass of the system is decreasing. In Table 3 the actual increase in momentum of the bell is compared to the summed momenta of the incre-

Table 3

Momentum and swimming efficiency in Polyorcbis montereyensis. A: Individual \#. B: Average mass of medusa and water contained in subumbrellar cavity (g). C: Mass of expelled water (g). D: Initial velocity $(\mathrm{cm} / \mathrm{sec})$. E: Increase in velocity during contraction $(\mathrm{cm} / \mathrm{sec})$. F: Area of velar aperture at the middle of the contraction phase $\left(\mathrm{cm}^{2}\right)$. G: Duration of contraction phase (sec). H: Increase in momentum of bell and enclosed water during contraction $(\mathrm{g} \mathrm{cm} / \mathrm{sec})$. J: Sum of momenta of increments of water expelled during contraction $(\mathrm{g} \mathrm{cm} / \mathrm{sec})$. K: Efficiency (" $\mathrm{H}^{\prime \prime / " J ") ~}$

\begin{tabular}{|cccccccccc|}
\hline $\mathrm{A}$ & $\mathrm{B}$ & $\mathrm{C}$ & $\mathrm{D}$ & $\mathrm{E}$ & $\mathrm{F}$ & $\mathrm{G}$ & $\mathrm{H}$ & $\mathrm{J}$ & $\mathrm{K}$ \\
\hline 1 & 8.8 & 2.4 & -0.1 & 1.8 & 0.65 & 0.33 & 16.0 & 35.0 & $41 \%$ \\
& 9.8 & 2.8 & 2.1 & 2.2 & 0.45 & 0.35 & 22.0 & 57.0 & $39 \%$ \\
2 & 2.1 & 0.43 & 0.0 & 1.5 & 0.22 & 0.19 & 3.1 & 6.4 & $48 \%$ \\
3 & 0.16 & 0.037 & 1.5 & 1.8 & 0.025 & 0.10 & 0.29 & 0.59 & $49 \%$ \\
4 & 0.25 & 0.074 & 1.6 & 1.6 & 0.035 & 0.15 & 0.41 & 1.22 & $34 \%$ \\
5 & 25.0 & 6.0 & 1.6 & 2.3 & 1.35 & 0.33 & 57.0 & 109.0 & $52 \%$ \\
& 22.6 & 5.2 & 0.4 & 2.5 & 1.2 & 0.34 & 56.0 & 88.0 & $64 \%$ \\
6 & 6.7 & 1.66 & 1.4 & 1.1 & 0.63 & 0.30 & 18.4 & 7.4 & $40 \%$ \\
\hline
\end{tabular}


ments of expelled water. The actual efficiency of the bell has been computed by dividing the total increase in momentum of the bell by the sum of the momenta of the expelled fractions of water.

In Table 2 the actual maximum velocities achieved, as well as the increase in velocity attained during one cycle of contraction are listed. In several instances an absolute velocity of $7 \mathrm{~cm} / \mathrm{sec}$ occurred at the height of a contraction. Generally however, the maximum velocity at the height of a contraction was about $4-6 \mathrm{~cm} / \mathrm{sec}$,

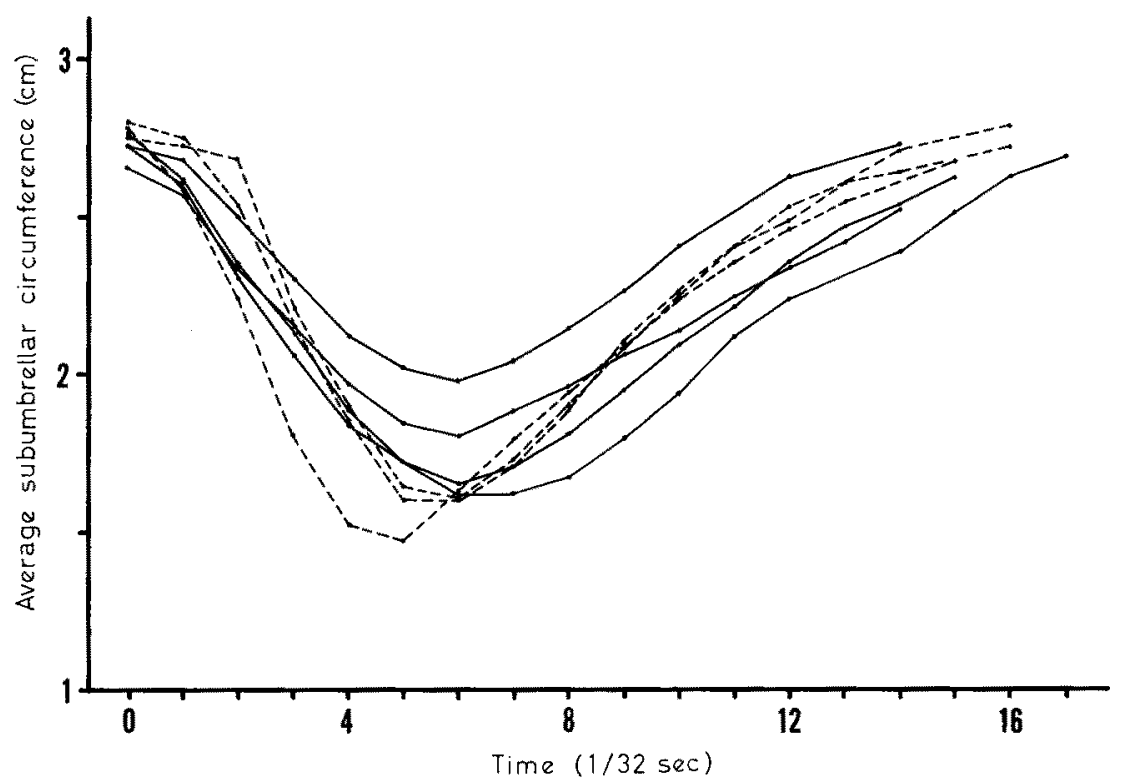

Fig. 21: Rates of contraction and recovery of the bell in an individual Polyorchis montereyensis before and after removal of the velum. Solid lines connect values for intact animal; dashed lines for the same animal after removal of the velum. Three differences are to be noted in comparing the contraction of the normal animal versus the animal after removal of the velum: (1) The rate of contraction is greater after temoval of the velum; (2) The initial recovery rate is greater after removal of the velum; and (3) The magnitude of the contraction is greater after removal of the velum

usually depending on the initial velocity. Generally the increase in velocity during the contraction was about $3 \mathrm{~cm} / \mathrm{sec}$. This was true regardless of the initial velocity. Thus, in a chain of successive contractions, maximum velocity is usually attained in the second beat. Smaller individuals achieve a greater velocity proportional to their size than do larger ones (Fig. 22); individuals of $15 \mathrm{~mm}$ or more in bell height achieve the same absolute velocity. Acceleration during contraction is greater for smaller than larger individuals: $15-20 \mathrm{~cm} / \mathrm{sec}^{2}$ in $15 \mathrm{~mm}$ high individuals, and usually more than $20 \mathrm{~cm} / \mathrm{sec}^{2}$ for individuals half as high.

Usually when $P$. montereyensis swims it does so in a sequence of seccessive swimming beats. Most often the recovery is just completed when the next contraction begins, but sometimes the second may begin before the recovery has been completed or 
may begin sometime atter completion of the recovery of the preceeding beat. During one of these sequences of beats a velocity of $3-5 \mathrm{~cm} / \mathrm{sec}$ is usually maintained.

From the preceeding discussion it is apparent that one role of the velum is to reduce the area of the aperture through which water exits from the bell, thus increasing its velocity, hence its momentum. Regardless of the actual efficiency of the bell as just discussed, an increase in the momentum of expelled water should bring about an increase in the momentum of the bell, hence a greater velocity. In order to test this hypothesis of the function of the velum, medusae were filmed as before, then the velum was carefully removed with fine iridectomy scissors, leaving its very base intact to insure that the nerves in the bell margin were not injured. In instances where the margin itself was cut, an animal did not resume swimming, as was noted by Romanes (1885) in Sarsia, though sporadic feeble contractions did occur. Measurements made on tracings of normal swimming sequences were compared with sequences of the same animals after removal of the velum. Several parameters of the swimming behavior were compared in animals before and after the operation: (1) the sequence of shape changes in the bell during contraction and recovery; (2) the magnitude and rate of contraction and recovery; and (3) acceleration and deceleration of the bell. These results are discussed below.

After removal of the velum in an animal, the contraction proceeds at a greater rate, achieves a greater magnitude, and is of shorter duration than when the velum was intact (Fig. 21). The initial recovery rate (for the first 30-50\% of the magnitude of the recovery) is also greater after the velum is removed. There is a simple mechanical explanation to these observations. With the medusa contracting and forcing water out through the small velar aperture, a hydrostatic pressure builds up in the subumbrellar cavity which opposes the efforts of the swimming muscle. After the velum has been removed however, the area of the aperture is $2-5$ times larger than normal, and no such hydrostatic pressure acts against the contracting muscle. The slower initial rate of recovery in the normal animal is probably due to the slowing down of the flow of water into the subumbrellar cavity by the velum. A negative hydrostatic pressure is probably created because the flow into the bell cavity is less than would be permitted by the elastic recovery forces in the bell. The increased recovery rate after removal of the velum, leaving a larger aperture, bears this out. The alternative explanation, that slower relaxation of muscles in the velum accounts for slower recovery in the normal individual, is unlikely because it is the marginal region which expands most rapidly at the beginning of recovery in the normal animal.

During the early part of the contraction the acceleration of the bell is just as great after removal of the velum as when the individual was intact. The rate of contraction, however, is greater in the absence of the velum. This phase of acceleration is of shorter duration in an animal without its velum, hence the increase in swimming velocity of such an animal is never as great as when the velum was intact. Acceleration of both normal and develumized animals closely corresponds to the rate of contraction (Fig. 21), hence maximum acceleration occurs roughly in the middle of the contraction phase, when the rate of contraction of the bell is greatest. The greatest rate of deceleration in both normal and develumized individuals occurs during the latter part of the contraction, not during recovery. An individual without its velum rapidly decel- 
erates to nearly the velocity it had at the start of the contraction, whereas the intact animal decelerates rapidly until the beginning of the recovery; then the decrease in velocity becomes very slow, and never drops to the initial velocity during a swimming sequence. The average velocity of an individual after removal of the velum is only about $50-70 \%$ of its velocity prior to removal.

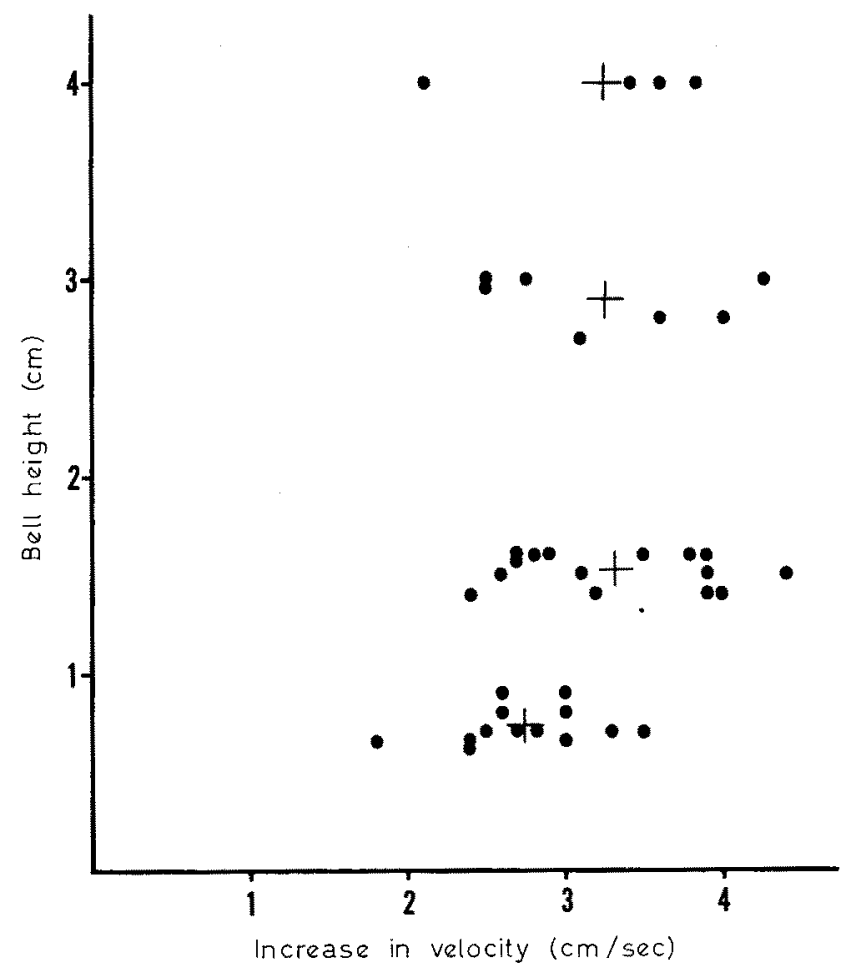

Fig. 22: Bell height versus the maximum gain in velocity during a contraction cycle. Each cross represents the average of all the values in that size class

From the preceeding discussion it is seen that the velum plays a very significant role in enhancing the swimming effectiveness of $P$. montereyensis. The sequence of shape changes is essentially the same before and after removal of the velum. The magnitude and rate of contraction, however, are actually greater in the absence of the velum (Fig. 21), yet the develumized bell is not nearly as effective in propelling the animal forward as the normal bell. The explanation has already been promulgated; i.e., by greatly reducing the aperture of the bell, the velocity of expelled water is greatly increased, even though the rate of contraction is slightly reduced by hydrom static pressure. Hence, a much greater momentum is imparted to the oppositely directed bell. The velum is effectively acting as a nozzle.

The effectiveness of the velum in constricting the aperture to the bell cavity is inversely proportional to the height of the bell (Table 4). In the resting condition the 


\section{Table 4}

Ratios of velar apertures to bell apertures in Polyorchis montereyensis. A: Individual \#. B: Bell height $(\mathrm{mm})$. C: Area of velar aperture/area of bell aperture at base of velum in relaxed condition. D: Same as "C", in contracted condition. E: "D" "C". F: Average of "E" values for each individual. G: Average of " $E$ " values for each size class. $H$ : Maximum velar height/ resting bell height

\begin{tabular}{|c|c|c|c|c|c|c|c|}
\hline A & B & C & D & E & $\mathrm{F}$ & G & $\mathrm{H}$ \\
\hline 1 & 40 & 0.59 & 0.72 & 1.22 & 1.22 & 1.2 & 0.14 \\
\hline 2 & 30 & & $\begin{array}{l}0.71 \\
0.64\end{array}$ & & & & $\begin{array}{l}0.09 \\
0.08\end{array}$ \\
\hline \multirow[t]{2}{*}{3} & 27 & 0.45 & $\begin{array}{l}0.50 \\
0.49\end{array}$ & 1.11 & 0.90 & 0.9 & $\begin{array}{l}0.16 \\
0.15\end{array}$ \\
\hline & & 0.48 & 0.33 & 0.69 & & & 0.13 \\
\hline 4 & 27 & & 0.45 & & & & 0.14 \\
\hline \multirow[t]{4}{*}{5} & 16 & 0.53 & 0.24 & 0.45 & 0.81 & & 0.04 \\
\hline & & 0.49 & 0.35 & 0.71 & & & 0.12 \\
\hline & & 0.42 & 0.53 & 1.26 & & & 008 \\
\hline & & 0.52 & & & & & \\
\hline 6 & 14 & 0.59 & 0.59 & 1.0 & 1.0 & & 0.11 \\
\hline 7 & 14 & 0.61 & 0.36 & 0.59 & 0.59 & 0.7 & $\begin{array}{l}0.12 \\
0.16\end{array}$ \\
\hline \multirow[t]{2}{*}{8} & 14 & 0.64 & 0.25 & 0.39 & 0.43 & & \\
\hline & & 0.53 & 0.25 & 0.47 & & & \\
\hline 9 & 7 & 0.56 & 0.34 & 0.61 & 0.61 & & \\
\hline \multirow[t]{5}{*}{10} & 7 & & 0.15 & & & & 0.12 \\
\hline & & 0.45 & 0.25 & 0.55 & & 0.5 & \\
\hline & & 0.58 & 0.18 & 0.31 & 0.48 & & \\
\hline & & 0.49 & 0.29 & 0.59 & & & \\
\hline & & & 0.08 & & & & 0.16 \\
\hline 11 & 7 & 0.49 & 0.19 & 0.39 & & & \\
\hline
\end{tabular}

ratio of the area of the velar aperture to that of the bell aperture at the base of the velum is about $0.5(0.4-0.6)$ regardless of the size of the individual. At maximum contraction however, the ratio ranges from 0.7 for larger individuals to 0.1 for smaller ones. There is a simple mechanical explanation for this. The contraction time increases roughly as the square root of the bell diameter (Fig. 20), whereas the subumbrellar water mass increases roughly as the cube of the diameter. Therefore the mass flow of water out of the subumbrellar cavity is much greater the larger the medusa is. The velum however, is a thin shelf of tissue, not much thicker in a large individual than in a small one, and its swimming muscle is identical per unit area. In a small medusa, therefore, the flow of water can be more or less contained by the velum, but in a large one it can not. This greater narrowing of the velar aperture explains in part the greater velocity relative to size attained in smaller individuals. This phenomenon of greater effectiveness of the velum in smaller individuals has broad significance with regard to the functional morphology and evolution of medusae, as will be discussed in another paper. 


\section{Turning}

The normal resting attitude of Polyorchis montereyensis in a tank of sea water is upright: the apex of the bell directly above the velar aperture. $P$. montereyensis has a specific gravity slightly greater than that of sea water, and thus slowly sinks when not swimming. Removal of the bell margin, including the ring canal, tentacles, and velum resulted in a buoyant bell less dense than sea water and a rapidly sinking marginal region. No differences in specific gravity between different portions of the bell mesoglea itself could be determined. A number of phenomena that can be considered as turning are caused by the differential buoyancy of the bell. An animal in the harbor or in a tank is often seen to swim toward the water surface, strike it, and rebound more or less in keeping with the laws of reflection. It then swims downward initially, but curves in an upward arc toward the surface due to its relatively dense marginal region and is once more reflected. Animals confined in a tank are also seen to rebound in like manner from the walls of the tank. Much of the observed turning of $P$. montereyensis is of this nature.

In a number of instances, however, the medusa exhibits turning behavior not accountable by reflection from surfaces, differential buoyancy or a permanently deformed bell. Such behavior was observed, for example, when an animal being filmed under bright lights occasionally turned and swam to the bottom of the photographic chamber, opposing the strong natural tendency of the buoyant apex of the bell to right itself (Fig. 23b). Such animals continued to swim in this inverted position for a time, but as soon as it ceased swimming, the bell quickly returned to its upright position. Twenty-five animals were placed in a large tank in a darkened room, and a 25 watt light bulb suspended to about middepth in a transparent cylinder. There was a definite aggregation of the animals in the vicinity of the light after a short time. It appears from these examples that $P$. montereyensis can turn in response to a photic stimulus, either positively or negatively. The physical mechanism by which such turning is effected is explained below.

When a turn is about to be executed, the contraction of circular muscles begins in the marginal region of the subumbrella of one side of the bell only, and apparently in the adjacent velum. As the contraction proceeds beyond this stage the entire bell and velum participate in the contraction, but the contraction remains strongest in that part of the bell where initiated. Viewing this situation in profile (Figs. 23b, c), the contraction becomes asymmetrical throughout. From the very beginning the width of the velum is less on the side where the contraction was initiated than on the opposite side (Fig. 23a). This can only be explained by a contraction of radial muscles in the exumbrellar side of the velum simultaneous to the contraction of the circular muscle, a situation quite analogous to that seen in the nectophores of the siphonophore Nanomia during reverse swimming (MACKIE 1964). It will be recalled that during straight swimming, the width of the velum increases significantly during contraction, due to shortening of its intrinsic circular muscle. In the present situation the entire velum increases in width as during straight swimming, but the antagonistic action of the radial muscles on the one side allows only a very slight increase in width of that portion of the velum, whereas circular muscle on the opposite side has no such active antagonist and can 
shorten considerably, increasing the velar width significantly (Fig. 23a). When the velum is extended, the bell begins to turn so that the marginal region opposite the region of initial contraction is forced away from the axis of locomotion, causing an

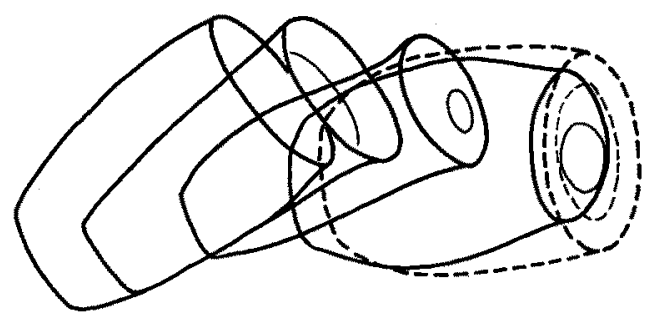

a
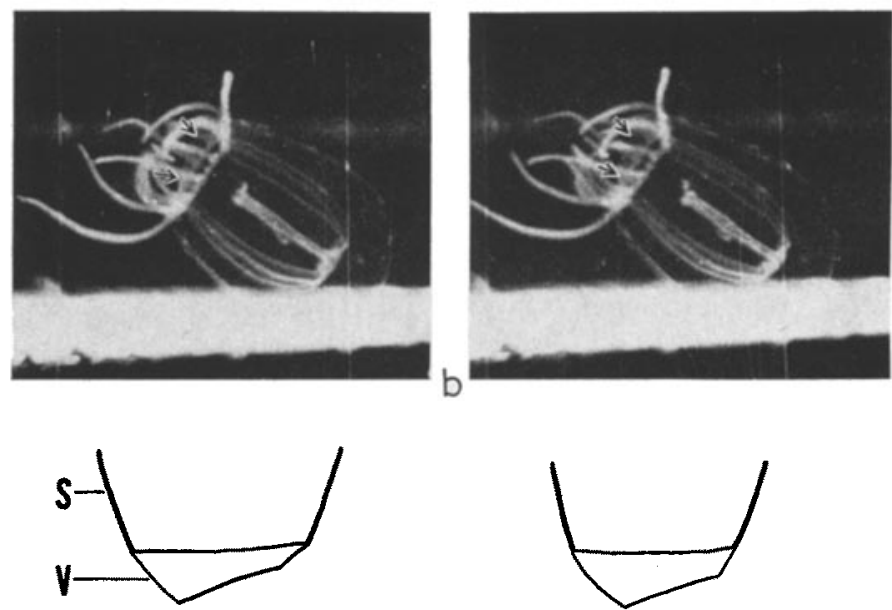

C

Fig. 23: The mechanism of turning in Polyorchis montereyensis. (a) Tracings from movie sequence, showing change in relative position of the subumbrellar outline with time. Bell initially at rest. Note the asymmetric shift of the velar aperture, the initially greater contraction of the subumbrellar on the inside of the turn, and the initiation of the actual turn well after the beginning of the contraction. Time interval equals $1 / 8 \mathrm{sec}$. (b) Enlargements from successive frames of a $16 \mathrm{~mm}$ movie sequence. The animal is turning toward the bottom of the tank in opposition to the strong tendency of the buoyant apex of the bell to right itself. Note the asymmetry of the extended velum. Time interval equals $1 / 32 \mathrm{sec}$. Arrows indicate corners of velar aperture as seen in lateral view. (c) Tracings of the velum of the preceding Figure $23 b$

angular displacement of the axis of the animal (Fig. 23a). Due to the differential contraction of velar muscles, the velum forms a nozzle obliquely directed toward what is to be the inside of the turn, and slightly displaced to that side. The water, by exiting in this direction, applies a net force to the lower part of the bell wall on what becomes the outside of the turning animal. Visual evidence of the direction of exiting water was 
provided in another anthomedusan genus Eupbysa, similar to $P$. montereyensis in having a tall cylindrical bell, by inserting milk into the subumbrellar cavity during filming of swimming. The greatest rate of angular displacement of the axis in $P$. montereyensis actually occurs near the end of the contraction and may even extend to the beginning of the recovery (Fig. 24a). Turning usually continues through the recovery period.

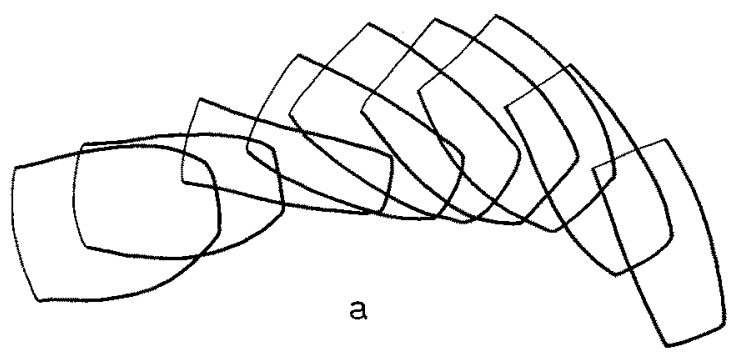

$0.2 \mathrm{~cm}$

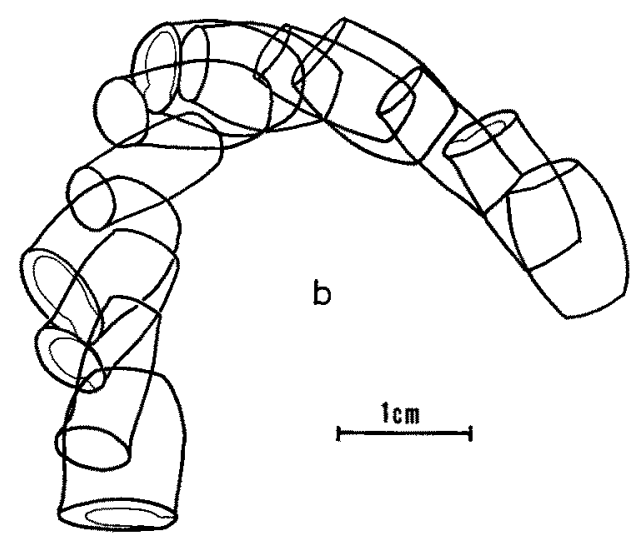

Fig. 24: Turning sequences of the subumbrellar profile of Polyorchis montereyensis showing actual change in position; traced from cinematographic sequences. (a) Normal turning sequence; (b) Sequence in which $1 / 4$ of the velum has been removed

To further confirm the action of the velum in effecting turning, a sector amounting to $15-25 \%$ of the circumference of the velum was removed by the method previously described. In the cases where this operation was performed, the animal swam in a relatively tight arc, with the side of the removed sector always on the inside of the turn (Fig. 24b). The effect of this operation was basically the same as the action previously discussed for the intact velum during turning; i.e., the velar aperture is displaced to the inside of the turn, creating a net force on the lower bell wall of the outside side.

A final observation made with reference to the mechanism of turning was that animals with the velum completely removed did not exhibit any active turning. 


\section{DISCUSSION}

Consideration of the swimming medusa as a functioning musculoskeletal system has been limited to casual treatment by G. Chapman $(1958,1959)$, Gutmann (1965, $1966 a, b, c)$ and D. M. Chapman (1968). Chapman (1958) has stated explicitly what many authors have recognized, that the medusa differs from most other musculoskeletal systems in that the muscles effecting locomotion are not arranged in antagonistic sets; instead, the swimming muscle is opposed by elastic forces generated in the mesogleal skeleton. The structure and properties of the mesoglea are thus important factors in the locomotory effectiveness of a medusa; they determine (1) to what degree a bell can be deformed and (2) at what rate it recovers.

The mesogleal skeleton varies considerably in consistency among different medusae, from the soft, flimsy substance of many leptomedusae to the tough rigid material of Dipbyes or Charybdea (GLADFELTER, unpublished). The precise nature of this difference in consistency is not known. The water content of the mesoglea has been determined for only a few medusae (HYMan 1940a, b, Chapman 1953a). The presence of collagen has been demonstrated in all medusae (in fact, all cnidarians) in which it has been looked for (PIEz \& Gross 1959, Chapman 1959, Mackie \& Mackie 1967). With the possible exception of Euphysa (see MACKIE \& MACKIE 1967) this collagen has been a component of the mesogleal matrix. The visible mesogleal fibers, on the other hand, have been shown by various staining procedures, electron microscopy, and especially by their physical properties, to be elastic (BouILLON \& VANDERMEERSSCHE 1957, Boumlon et al. 1958). Collagenous fibers are inelastic in nature. CHAPMAN $(1953 a, 1959,1966)$ has contended that the visible mesogleal fibers are collagenous, but it appears he may have confused the submicroscopic collagenous fibers for the visible elastic ones (Mackie \& Mackie 1967). However, the large fibers of Pelagia shrink considerably on heating (CHAPMAN 1959), which presumably is characteristic of collagen but not elastin. Alexander (1964) has suggested that the visible mesogleal fibers are "concentrations fo the matrix". The visible fibers have been shown to be associated with mucopolysaccharides by CHAPMAN (1953a, 1959).

The percentage of organic matter (less than $1 \%$ ) in the mesoglea (CHAPMAN 1953a) is much lower than the percentage of gelatin giving rise to a firm gel. Because of this very low proportion of organic matter, the submicroscopic structure of the mesoglea is visualized as a loose, 3-dimensional lattice of cross-linked collagenous fibers enclosing pockets of both bound and free water. Whatever the structure at this level, it must permit complete, elastic recovery of the fully deformed bell to its expanded condition. This is essentially similiar to the macromolecular structure of the sea anemone as visualized by GosinNe (1969).

The presence of the visible mesogleal fibers has been described by numerous authors (Alvarado 1923, Tretyakoff 1937, Chapman 1953a, 1959, Mackie \& MACKIE 1967, etc.), but before the present work an account of their distribution has been provided only by Tretrakoff (1937), in Scyphozoa. Numerous illustrations, both drawings and photographs, depict the nature of the fibers, but all the photos show the fibers in the contorted, roughly helical conformation assumed as a result of shrinkage of the matrix during fixation (MACKIE \& MACKIE 1967). Only by working with fresh 
or freshly HCHO fixed material can the true, straight condition of the fibers be seen (Fig. 8).

The distribution of fibers suggests that their function is to maintain the radial integrity of those portions of the mesoglea that thicken during contraction; they act essentially as springs as was discussed. The fibers may be important in effecting recovery as was suggested by CHAPMAN (1966), but the compressional component of deformation seems to be more significant than the radial in opposing the action of the contracting muscle, thus in being the major component in effecting recovery. CHAPMAN (1953a) has pointed out that in sea anemones, the visible fibers seem to be oriented in the directions of stress.

In no anthomedusan has the presence of a joint system been recognized, though Agassiz (1862) has clearly depicted them and erroneously labelled these regions as "sinuses". D. M. Chapman (1962) has published a fine electron micrograph of the joint mesoglea in Ampbinema, without comment, but has later mentioned the presence of this inner layer of mesoglea (CHAPMAN 1968), though he incorrectly states that this inner mesoglea is absent in Neoturris.

Physical properties of the mesoglea of medusae have been studied by CHapman (1953b) and AleX.ANDER (1964). These authors have dealt only with visco-elastic strain as a function of stress applied over a long period of time (hours), and as has been stated by Alexander (1964) himself, these studies are not ... " $\ldots$ of any functional importance in jellyfish, as the distortions of the bell in swimming are completed in periods of the order of one second." That is, during the fraction of a second required to bring about the full deformation of the bell, the mesogleal strain is purely elastic and essentially instantaneous, hence very difficult to measure. The recovery of the bell to its expanded condition after such a brief period of deformation, is both rapid and complete. Longer term deformations occur when the medusa undergoes its so-called "crumpling" reaction (HYMAN 1940b). Even during these contractions the strain appears to be purely elastic since recovery is complete, but this is a slow elastic strain (Alexander 1964), and may well involve a different type of deformation at the submicroscopic or molecular level.

Besides serving as the skeleton for the support of the various structures of a medusa, and as an elastic antagonist for the swimming muscle, the mesoglea also serves to increase the buoyancy of a medusae (DeNTON 1963). It has long been known that in a few medusae, the chloride to sulfate ratio is considerably greater in the mesoglea than in sea water (Chapman 1966). Recently, however, Mackay (1969) has demonstrated the actual excretion of sulfate in several hydromedusae.

The swimming muscle of medusae is universally striated and apparently is an evolutionary development quite distinct from the striated muscle in other metazoa. This muscle is essentially a two dimensional sheet, though by the process of folding of the epithelium the amount of contractile tissue has been greatly increased for a given area of subumbrellar surface in some medusae (KRAsinska 1914, GLADFELTER, unpublished). In Neoturris and Aequorea (see Krasinska 1914) there are two adjacent layers of subumbrellar epithelial cells. The cells of the more superficial layer bear radial smooth muscle processes, while the cells of the deep layer bear circular striated fibers. The morphology of the individual epitheliomuscular cells varies considerably in differ- 
ent medusae (Hertwig \& Hertwig 1878, Krasinsma 1914, Fraser 1962, D. Chapman 1968). The HeRTwigs (1880) have demonstrated a series of stages in the evolution of muscle fibers that are completely separated from the parent epithelium. KrasinsKa (1914) has enlarged the series. Published electron micrographs of Kawaguti \& HaMAKOSHI (1963), CHAPMAN et al. (1962), and unpublished electron micrographs of FrASER gibe a clear picture of the structure of the epitheliomuscular cells in the forms studied. The illustrations of Bouncoon et al. (1958) are less informative. Certainly, further electron microscopic studies of epitheliomuscular cells could provide valuble comparative information on the swimming mechanism in medusae.

The existence of a musculoskeletal system in medusae implies anchorage of the swimming muscle to the skeleton, i.e., the bell mesoglea. In $P$. montereyensis with eight adradial joints there are eight lines of anchorage in the per- and interradii. The actual nature of the muscle anchorage is not clear, though at the level of light microscope studies (in P. montereyensis, for example) it can be seen that this anchorage is mediated through the basement membranes of the subumbrellar epidermis and the gastrodermal lamella.

The function of the hydrozoan velum had not been adequately studied before the present work was done. MAckiE's analysis (1964) of the velar action during foward and reverse swimming in the nectophores of Nanomia is probably the only available analysis of velar function, and it treats a specific aspect of velar function in a highly specialized hydrozoan. The participation of the velum in swimming has been mentioned by HYman (1940a) and others, but these statements have evidently been based on casual observations alone. Based on the present study, the velum has two primary functions: (1) during straight swimming, to narrow the aperture through which water exits from the subumbrellar cavity, thus increasing its velocity and momentum, and (2) during turning, to displace this aperture so that water exits asymmetrically.

Studies on the function of the velum in different size classes of $P$. montereyensis indicate that in small individuals of a particular species the velum plays a proportionately more important role during swimming than in large individuals. As was discussed earlier this is because of the proportionally greater volumn flow of water through the velum in larger individuals.

\section{SUMMARY}

1. The structure and function of the locomotory system of the anthomedusan Polyorchis montereyensis SKogsberg were studied in detail. Anatomical investigations were carried out primarily on fresh or formalin fixed specimens; histology was done on specimens fixed in Bouin's fluid. Functional analyses were based largely on photography and cinematography.

2. Swimming in $P$. montereyensis involves the alternating antagonistic action of the subumbrellar swimming muscles and the elastic mesoglea.

3. The swimming muscle consists of striated contractile elements arranged circularly in four discontinuous subumbrellar sheets and a sheet on the subumbrellar side of the velum. There is also a sheet of radially arranged fibers on the exumbrellar side 
of the velum. The four subumbrellar sheets are anchored to the bell along the perand interradii.

4. The mesogleal skeleton consists of five components: (a) the matrix of the bell mesoglea, (b) optically visible fibers that traverse the bell from gastrodermal lamella to exumbrella, (c) the basement membrane or supporting lamella, (d) a system of joints, and (e) the velar mesoglea.

5. The morphology, orientation, and distribution of the mesogleal fibers suggest that their major role is maintaining the radial integrity of the bell during deformation. The amount of stretch in a region of the bell wall during contraction is inversely proportional to the number of fibers per unit area there. In regions of the bell which are not deformed during contraction fibers are sparse or absent.

6. Mesogleal volume remains constant during swimming. Locally the mesoglea is subjected to forces of stretch and compression, but the critical element in narrowing the bell involves bending or folding the mesoglea around a series of structural joints. The fulcrum of these joints is anchored to the exumbrella by concentrations of mesogleal fibers. The joints consist of eight adradial regions of highly deformable mesoglea lacking visible fibers. The regions are triangular in cross section and are separated from the remainder of the mesoglea (98-99\% of the total) by the gastrodermal lamella. A circular apical joint is also present.

7. Sequential changes in shape and position of the bell relative to a fixed grid during contraction and recovery were measured in order to determine such parameters of swimming as rate of contraction, rate of expulsion of water, change in bell velocity during contraction and recovery, momentum, etc.

8. The function of the velum was determined by cinematographic analysis of swimming animals both before and after removal of the velum. In normal swimming the velum serves mainly to constrict the aperture of the bell, thus increasing the velocity of expelled water, and hence increasing the force driving the medusa foward. Medusae swam with a greatly decreased velocity after velum removal.

9. Turning is accomplished primarily by asymmetrical contraction of the exumbrellar velar radial muscles, whereby the velar aperture is displaced to one side, water is expelled obliquely, and the bell turns toward that same side. The ability to turn was lost after velum removal.

10. Studies of the relationship between individual size and the various parameters of swimming in $P$. montereyensis show that: (a) the duration of the contraction phase of the swimming beat is roughly proportional to the square root of the subumbrellar circumference (or bell height); (b) smaller individuals swim faster relative to their bell height than do larger ones; (c) the velum is relatively better developed in small animals and plays a proportionately more important role during swimming.

Acknoweledgements. I wish to thank above all my major Professor D. P. ABвotr of the Hopkins Marine Station, whose insight and encouragement made this work possible. I also wish to thank G. O. MACKIE of the University of Victoria and G. CHAPMAN of the University of London for reading the manuscript and offering helpful suggestions. My wife BErsy performed numerous helpful chores for which I am grateful. This work was carried out while I was under the tenure of a National Science Foundation Graduate Fellowship at the Hopkins Marine Station of Stanford University, U.S.A. 


\section{LITERATURE CITED}

Agassiz, L., 1862. Contributions to the natural history of the United States of North America 4, 1-380.

Azexander, R. M., 1964. Visco-elastic properties of the mesoglea of jellyfish. J. exp. Biol. 41, 363-369.

Alvarado, S., 1923. Sobre la estructura de la substancia fundamental de la mesogloea de las hidromedusas. Boln Soc. esp. Hist. nat. 23, 167-173.

BAUER, V., 1927. Die Schwimmbewegungen der Quallen und ihre reflektorische Regulierung. Z. vergl. Physiol. 5, 37-69.

Boullon, J., Castiaux, P. \& Vandermeerssche, G., 1958. Musculature de la Méduse Limnocnida tanganyicae. Bull. Microsc appl. (Ser. 2) 8, 81-87.

- \& VANDermeerssche, G., 1957. Structure et nature de la mesoglee des hydro- et scyphomeduses. Annls Soc, r. zool. Belg. 87, 9-25.

Chapman, D. M., 1968. A new type of muscle cell from the subumbrella of Obelia. J. mar. biol. Ass. U.K. 48, 667-688.

- Pantin, C. F. A. \& Robson, E. A., 1962. Muscle in coelenterates. Revue can. Biol. 21, 267-278.

Chapman, G., 1953a. Studies of the mesoglea of coelenterates. I. Histology and chemical properties. Q. Jl microsc. Sci. 94, 155-176.

- 1953b. Studies of the mesoglea of coelenterates. II. Physical properties. J. exp. Biol. 30, $440-451$.

- 1958. The hydrostatic skeleton of the invertebrates. Biol. Rev. 33, 338-371.

- 1959. The mesoglea of Pelagia noctiluca. Q. J1 microse. Sci. 100, 599-610.

- 1966. The structure and function of the mesoglea. In: The cnidaria and their evolution. Ed. by W. J. Rees. Academic Press, New York, 147-168.

DENTON, E. J., 1963. The buoyancy mechanism of sea creatures. Endeavour 22, 85-87.

EAKIN, R. M. \& WeSTFALL, J., 1962. Fine structure of photoreceptors in the hydromedusan, Polyorchis penicillatus. Proc. natn Acad. Sci. U.S.A. 48, 826-833.

Fraser, L. A., 1962. The histolgy of the musculature of Gonionemus. Trans. Am. microsc. Soc. 81, 257-262.

GALIGHER, A. E. \& KozLOFF, E.N., 1964. Essentials of practical microtechnique. Lea \& Febiger, Philadelphia, $484 \mathrm{pp}$.

Gosline, J., 1969. A macromolecular model of the mesoglea of a sea anemone. Am. Zool. 9, 1115.

GutmanN, W. F., 1965. Rückstoß und Ruderschlag der Quallen. Natur Mus. 95, 455-464.

- 1966a. $\mathrm{Zu} \mathrm{Bau} \mathrm{und} \mathrm{Leistung} \mathrm{von} \mathrm{Tierkonstruktionen.} \mathrm{2.} \mathrm{Die} \mathrm{Glocke} \mathrm{von} \mathrm{Rbizostoma} \mathrm{octo-}$ pus. Natur Mus. 96, 103-108.

- 1966b. Zu Bau und Leistung von Tierkonstruktionen. 3. Die Lage der inneren Organe in rüdsstoßschwimmenden Tieren. Natur Mus. 96, 195-204.

- 1966c. Zu Bau und Leistung von Tierkonstruktionen 4-6. Abh. senckenb. naturforsch. Ges. 510, 1-106.

Hertwig, O. \& Hertwig, R., 1878. Das Nervensystem und die Sinnesorgane der Medusen. Vogle, Leipzig.

- - 1880. Der Organismus der Medusen und seine Stellung zur Keimblättertheorie. Denkschr. med.-naturw. Ges. Jena 2, 1-70.

Hyman, L. H., 1940a. The invertebrates: Protozoa through ctenophora. McGraw-Hill, New York. 1, 1-726.

- 1940b. Observations and experiments on the physiology of medusae. Biol. Bull. mar. biol. Lab., Woods Hole 79, 282-296.

Kawagutr, S. \& Tadatoshi, H., 1963. Electron microscopic studies on striated and smooth muscles of an anthomedusan, Spirocodon saltatrix. Biol. J. Okayama Univ. 9, 127-139.

Krasinska, S., 1914. Zur Histologie der Medusen. Z. wiss. Zool. 109, 256-348.

Litrue, E. V., 1914. The structure of the ocelli of Polyorcbis penicillatus. Univ. Calif. Publs Zool. 11, 307-328. 
Mackax, W. C., 1969. Sulfate regulation in jellyfish. Comp. Biochem. Physiol. 30, 481-488.

Mackie, G. O., 1964. Analysis of locomotion in a siphonophore colony. Proc. R. Soc. (B) 159, 366-391.

- \& Mackie, G. V., 1967. Mesogleal ultrastructure and reversible opacity in a transparent siphonophore. Vie Milieu (A) 18, 47-71.

- \& Passano, L. M., 1968. Epithelial conduction in hydromedusae, J. gen. Physiol. 52, 600-621.

Nagao, Z., 1963. The early development of the anthomedusa, Polyorchis karafutoensis Kishinouye. Annotnes zool. jap. 36, 187-193.

PIEz, K. A. \& Gross, J., 1959. The amino acid composition of some invertebrate and vertebrate collagens. Biochim. biophys. Acta 34, 24-39.

Romanes, G. J., 1885. Jelly-fish, star-fish and sea urchins: a research on primitive nerrous systems. Appleton, New York.

Skogsberg, T., 1948. A systematic study of the family Polyorchidae. Proc. Calif. Acad. Sci. 26, 101-124.

TreTyakoff, D. K, 1937. Russk. Arkh. Anat. Gistol. Émbriol. 17, 279.

Author's address: Dr. W. B. GLADFELTER

Pacific Marine Station

Dillon Beach, California 94929

USA 